\title{
Redox regulation of the protein tyrosine phosphatase PTP1B in cancer cells
}

\author{
Yi-Wei Lou ${ }^{1,2, *}$, Yi-Yun Chen ${ }^{1,2,3, *}$, Shu-Fan Hsu ${ }^{1,2}$, Ren-Kun Chen ${ }^{3}$, Chih-Lei Lee ${ }^{3}$, \\ Kay-Hooi Khoo ${ }^{1,2,3} \dagger$, Nicholas K. Tonks ${ }^{4,} \dagger$ and Tzu-Ching Meng ${ }^{1,2,} \dagger$ \\ 1 Institute of Biological Chemistry, Academia Sinica, Taipei, Taiwan \\ 2 Institute of Biochemical Sciences, College of Life Sciences, National Taiwan University, Taipei, Taiwan \\ 3 National Core Facility for Proteomics Research, Academia Sinica, Taipei, Taiwan \\ 4 Cold Spring Harbor Laboratory, NY, USA
}

\begin{abstract}
Keywords
cancer cells; mass spectrometry; protein tyrosine phosphatase; PTPIB; reactive oxygen species
\end{abstract}

\section{Correspondence \\ K.-H. Khoo, Institute of Biological Chemistry, Academia Sinica, 128 Academia Road, \\ Section 2, Taipei 11529, Taiwan \\ Fax: +886 227889759 \\ Tel: +886 227855696 \\ E-mail: kkhoo@gate.sinica.edu.tw \\ N. K. Tonks, Cold Spring Harbor Laboratory, \\ 1 Boungtown Road, Cold Spring Harbor, NY 11724, USA \\ Fax: +1516 3676812 \\ Tel: +1 5163678846 \\ E-mail: tonks@cshl.edu \\ T.-C. Meng, Institute of Biological \\ Chemistry, Academia Sinica, 128 Academia \\ Road, Section 2, Taipei 11529, Taiwan \\ Fax: +886 227892161 \\ Tel: +886 227855696 \\ E-mail: tcmeng@gate.sinica.edu.tw}

*These authors contributed equally to this work

†This manuscript is a joint communication of these authors

(Received 10 August 2007, revised 27 Octo-

ber 2007, accepted 1 November 2007)

doi:10.1111/j.1742-4658.2007.06173.x

Protein tyrosine phosphatases (PTPs) comprise a large family of enzymes that are critical regulators of signal transduction. The normal function of PTPs is required
The oxidation and inactivation of protein tyrosine phosphatases is one mechanism by which reactive oxygen species influence tyrosine phosphorylation-dependent signaling events and exert their biological functions. In the present study, we determined the redox status of endogenous protein tyrosine phosphatases in HepG2 and A431 human cancer cells, in which reactive oxygen species are produced constitutively. We used mass spectrometry to assess the state of oxidation of the catalytic cysteine residue of endogenous PTP1B and show that this residue underwent both reversible and irreversible oxidation to high stoichiometry in response to intrinsic reactive oxygen species production. In addition, our data show that the oxidation of PTP1B is specific to the active site Cys, with the other Cys residues in the protein remaining in a reduced state. Treatment of these cells with diphenyleniodonium, an inhibitor of NADPH oxidases, decreased reactive oxygen species levels. This resulted in inhibition of protein tyrosine phosphatase oxidation, concomitant with decreased tyrosine phosphorylation of cellular proteins and inhibition of anchorage-independent cell growth. Therefore, our data also suggest that the high level of intrinsic reactive oxygen species may contribute to the transformed phenotype of HepG2 and A431 cells via constitutive inactivation of cellular protein tyrosine phosphatases.

\section{Abbreviations}

DPI, diphenyleniodonium; Nox, NADPH oxidase; PTP, protein tyrosine phosphatase; ROS, reactive oxygen species; RPTP, receptor-like protein tyrosine phosphatase. 
survival, metabolism and motility [1]. Analyses of the human genome sequence have revealed that the PTP superfamily is encoded by $\sim 100$ PTP genes and includes 37 classical, phosphotyrosine-specific phosphatases as well as $\sim 60$ that are currently described as dual specificity phosphatases, which recognize $\mathrm{p}-\mathrm{Ser} / \mathrm{p}$-Thr and p-Tyr residues in proteins as well as non-protein substrates [2]. Although there is structural diversity within the PTP family, these enzymes are characterized by a signature motif [I/V]HCXXGXXR[S/T], which contains an invariant Cys residue that is essential for catalysis [1]. The environment of the active site confers an unusually low $\mathrm{pK} \alpha$ on this Cys [3,4], which therefore is present as a thiolate anion at neutral $\mathrm{pH}$. This unique feature is critical in enhancing the ability of this catalytic Cys to function in nucleophilic attack on the phosphate group of the substrate; however, the low $\mathrm{pK} \alpha$ also renders this residue highly susceptible to oxidation, with concomitant inhibition of PTP activity [5].

Many investigations have illustrated the importance of NADPH oxidases (Noxs) in controlling cellular redox status [6,7]. The prototypic Nox was identified in phagocytes and shown to be an important component of the respiratory burst. It is clear that Nox isoforms are present in cells derived from various tissues producing reactive oxygen species (ROS) in response to extracellular stimuli, although at lower levels than in phagocytes [8,9]. A substantial body of evidence has demonstrated that the intracellular redox state is highly dynamic and tightly regulated by the coordinated actions of enzyme systems that generate and remove ROS [10]. It is now appreciated that ROS, such as $\mathrm{H}_{2} \mathrm{O}_{2}$, function as second messengers in the regulation of tyrosine phosphorylation-dependent signaling events in response to extracellular stimuli $[10,11]$. In order to act in propagating a signaling response to extracellular stimuli, ROS regulate posttranslational modifications of cellular proteins, thereby controlling the function of those proteins. The unique biochemical and structural characteristics of the active site Cys in PTPs engendered the hypothesis that these enzymes might be direct targets of ROS.

In principle, mild oxidation of Cys leads to the formation of a sulfenic acid derivative (Cys-SOH) or a cyclic sulfenamide species [12-14], either of which would reflect a reversible modification. By contrast, higher levels of oxidants may convert the Cys residue to either sulfinic $\left(\mathrm{Cys}-\mathrm{SO}_{2} \mathrm{H}\right)$, or sulfonic $\left(\mathrm{Cys}-\mathrm{SO}_{3} \mathrm{H}\right)$ acid [12-14], which normally results in an irreversible modification. Because the oxidized Cys could no longer function as a nucleophile, oxidation would abrogate the enzymatic activity of those PTPs that have encountered ROS. Indeed, previous studies performed in vitro have demonstrated that several PTPs, such as PTP1B, leukocyte antigen-related and vaccinia H1-related phosphatases, were inactivated in response to treatment with $\mathrm{H}_{2} \mathrm{O}_{2}$ [5]. Consequently, it was proposed that redox-dependent regulation may be a general mechanism for the control of cellular PTP activity in various signaling contexts. This hypothesis was further supported by reports that ROS facilitated the inhibition of PTP activity and activation of tyrosine phosphorylation-dependent signaling pathways in cells in response to a broad spectrum of extracellular ligands [15-21].

The assays currently used to measure PTP oxidation are indirect, and performed by assessing enzymatic activity or susceptibility of the active site Cys to alkylation. However, the various oxidation states of the Cys residue in the PTP active site signature peptide can be resolved by MS. In the present study, we applied MS-based analysis to characterize the state of oxidation of the invariant catalytic Cys of PTP1B in HepG2 and A431 human cancer cells, in which we have shown that ROS were produced constitutively. Our data demonstrate that, in the presence of the high ROS levels generated in these cells, the catalytic Cys of endogenous PTP1B is subject to both reversible and irreversible oxidation. Surprisingly, more than $65 \%$ of the total pool of PTP1B in these cells was in an oxidized and inactivated state. Moreover, we show that the ROS produced in these cells act to promote tyrosine phosphorylation-dependent signaling and anchorage-independent growth, indicating a potential role of the constitutively-produced ROS in maintaining the transformed phenotype of HepG2 and A431 cells.

\section{Results}

\section{Constitutive production of ROS occurs concomitantly with reversible inactivation of endogenous PTPs in human cancer cells}

To examine the redox-dependent regulation of endogenous PTPs in a biological model, we turned our attention to human cancer cells, which produce ROS in a sustained manner, in contrast to untransformed cells in which ROS are normally produced transiently in response to extracellular stimuli $[11,22,23]$. We evaluated the level of $\mathrm{H}_{2} \mathrm{O}_{2}$ produced by four cancer cell lines derived from human carcinomas. Following a time course of incubation with Amplex Red, which is converted to a fluorescent derivative when it encounters $\mathrm{H}_{2} \mathrm{O}_{2}$ in culture media, we observed that the hepatoma HepG2 cells and epidermoid carcinoma A431 cells produced substantial ROS (Fig. 1A) and we focused attention on these cells for further study. 
Fig. 1. Multiple PTPS are reversibly oxidized in HepG2 and A431 human cancer cells that produce significant levels of ROS. HepG2 $(\mathrm{HG}), \mathrm{A} 431$ (A), HeLa (HL) and Caco-2 (C) human cancer cells were utilized in these experiments. (A) Cells $\left(1.5 \times 10^{4}\right)$ were incubated with Amplex Red in serum-free KRPG buffer for 0, 10, 30 and $60 \mathrm{~min}$. The levels of ROS released into the culture medium were quantitated by a fluorescence microplate reader. Units shown are arbitrary and are the mean \pm SE of triplicate experiments. (B) Serum-starved cells were lysed in the absence (-) or presence (+) of $100 \mathrm{~mm}$ iodoacetamide (IAA). An aliquot of total lysate $(25 \mu \mathrm{g})$ was subjected to in-gel phosphatase activity assay (upper panel) or immunoblotting with anti-actin serum (lower panel). Arrowheads indicate PTPs resistant to iodoacetamide-mediated alkylation, reflecting that their catalytic Cys residue might be reversibly oxidized in cells. (C) Endogenous PTP1B was immunoprecipitated from HepG2 and A431 lysates $(100 \mu \mathrm{g})$ with anti-PTP1B serum FG6 $(5 \mu \mathrm{g})$. An aliquot of lysate $(25 \mu \mathrm{g})$, immunocomplex and supernatant post-immunoprecipitation $(25 \mu \mathrm{g})$ was subjected to in-gel phosphatase activity assay (upper panel) or immunoblotting with anti-actin serum (lower panel). The arrowhead indicates the position of endogenous PTP1B that was immunodepleted by anti-PTP1B serum FG6 from total lysate.

To test the effect of constitutively produced ROS on PTP oxidation and inactivation, cells were harvested under anaerobic conditions in the absence (Fig. 1B, lanes 1-4) or presence (Fig. 1B, lanes 5-8) of iodoacetamide, which irreversibly carbamidomethylated Cys residues of any cellular PTPs that were in the reduced form. By contrast, any Cys residues in PTPs that had been oxidized in response to ROS were resistant to carbamidomethylation by iodoacetamide. An aliquot of lysate was then subjected to a standard in-gel phosphatase activity assay. Upon completion of electrophoresis, the gel, which had been cast to contain a ${ }^{32}$ P-labeled substrate, was sequentially processed in denaturation buffer, then renaturation buffer in the presence of reducing agents, leading to the reactivation of those PTPs that were reversibly oxidized in cells. We observed that, out of the spectrum of PTPs that were detectable in cell lysates (Fig. 1B, lanes 1-4), three PTPs, with a respective approximate molecular mass of 115,50 and $45 \mathrm{kDa}$, underwent reversible oxidation in HepG2 and A431 cells (Fig. 1B, lanes 5-6). As shown in Fig. 1B (lanes 7-8), the $45 \mathrm{kDa}$ PTP was also reversibly oxidized, although to a lesser extent, in HeLa and Caco-2 cells.

To explore further the molecular basis for the ROSmediated modification of PTP activity, it was essential to identify those reversibly oxidized phosphatases. We focused our attention on the $50 \mathrm{kDa}$ PTP because its reversible oxidation occurred to the greatest extent in the cells that produced higher levels of ROS (Fig. 1). On the basis of its $M_{\mathrm{r}}$, we hypothesized that the phos-

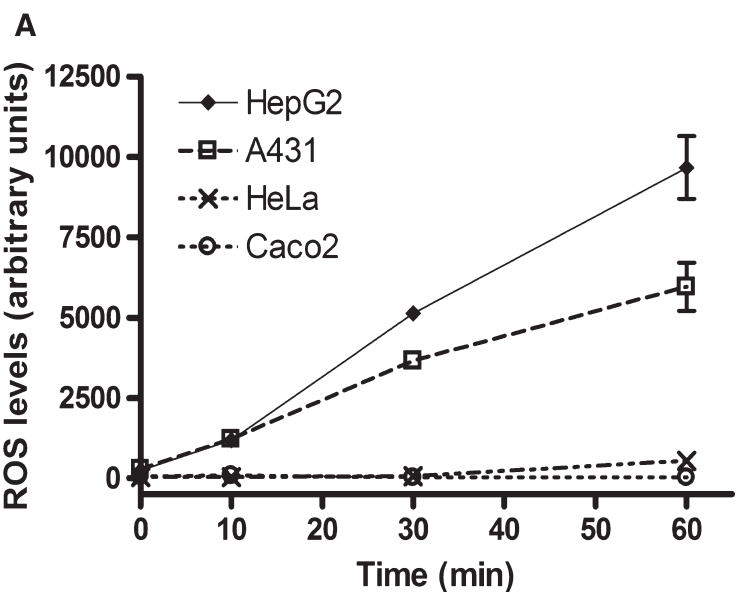

B Cell: HG A HL C HG A HL C

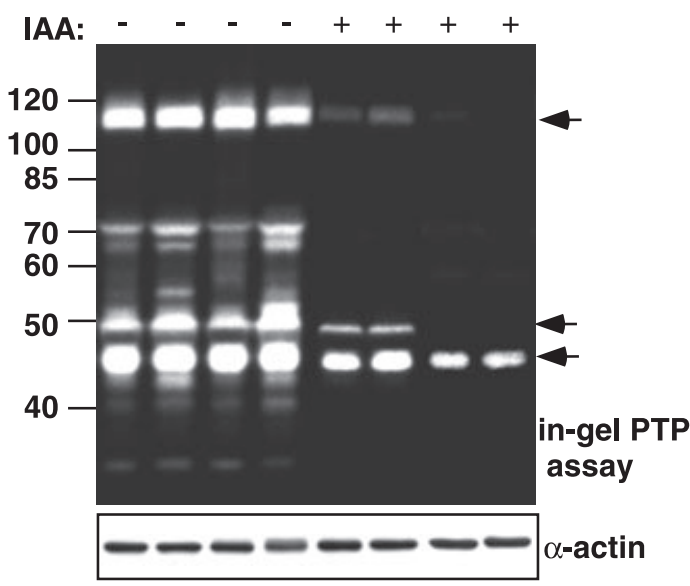

C

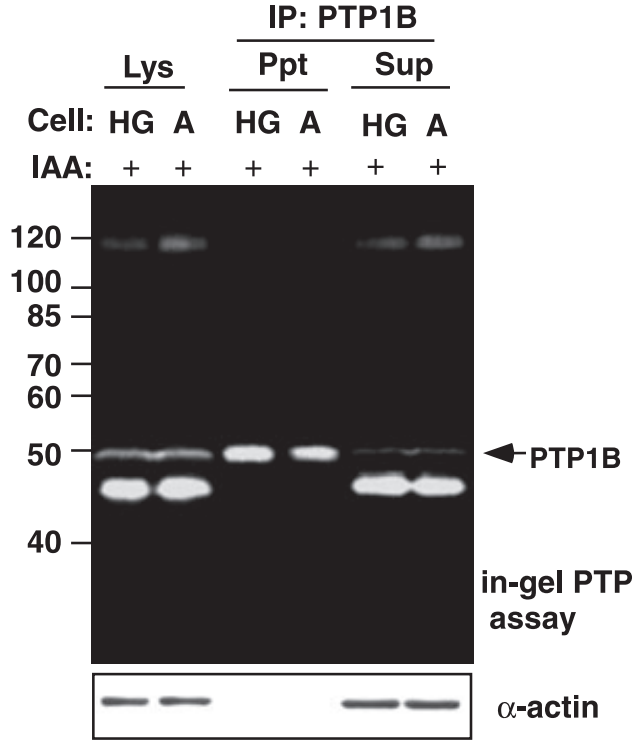

phatase might be PTP1B. Using immunodepletion, together with an in-gel phosphatase activity assay, we observed that the anti-PTP1B serum FG6 effectively 
immunoprecipitated from the lysate the $50 \mathrm{kDa}$ PTP that was reversibly oxidized in HepG2 and A431 cells (Fig. 1C).

\section{An MS-based strategy to identify oxidation of catalytic Cys residues in PTPs}

We wished to develop an analytical platform by which to measure directly redox-dependent modification of PTPs in vivo. For this purpose, we undertook the MS-based strategy that is outlined in Fig. 2. As indicated, ROS produced under physiological conditions, such as $\mathrm{H}_{2} \mathrm{O}_{2}$, may induce different degrees of oxidation of Cys residues. In the presence of iodoacetamide, the various oxidized forms of the Cys

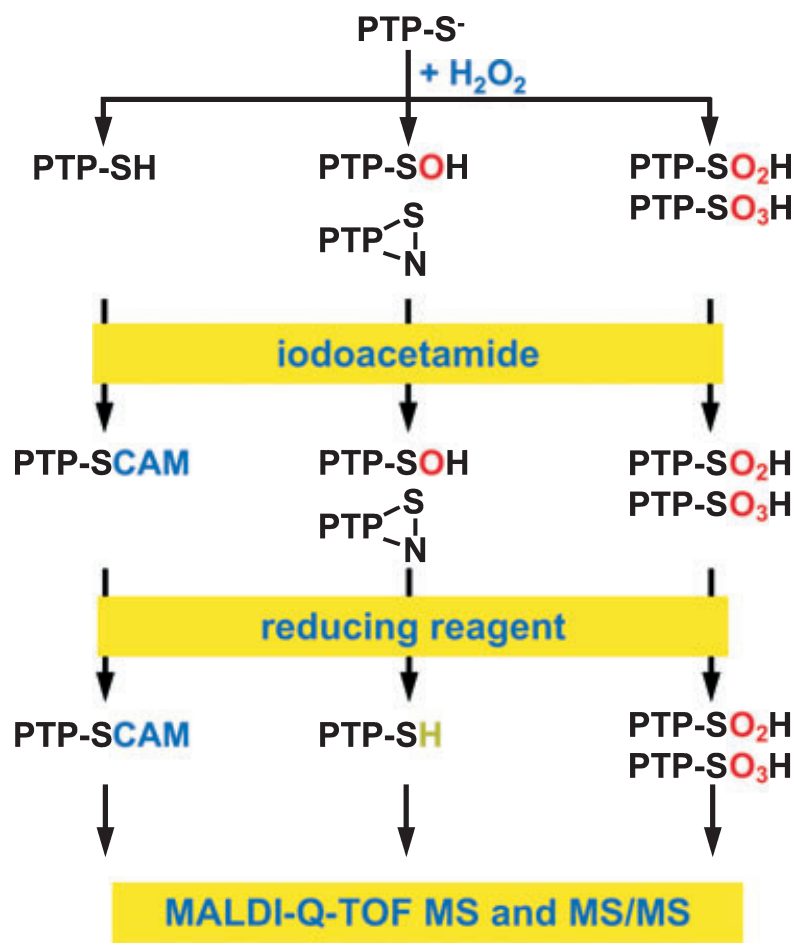

Fig. 2. A MS-based strategy to identify oxidative modifications of Cys residues in PTPS. ROS trigger oxidative modifications of the active site Cys residues in PTPs that may lead to the formation of reversible sulfenic acid (-SOH) and sulfenamide (-S-N) derivatives, or irreversible sulfinic acid $\left(-\mathrm{SO}_{2} \mathrm{H}\right)$ and sulfonic acid $\left(-\mathrm{SO}_{3} \mathrm{H}\right)$ derivatives. By contrast, PTPs that do not encounter ROS remain in the reduced, thiolate anion $\left(-S^{-}\right)$form. After alkylation with iodoacetamide followed by SDS/PAGE under reducing conditions, Cys residues in the reduced state will be carbamidomethylated (-CAM), whereas the reversibly oxidized Cys, which is resistant to alkylation, will be reduced to Cys-SH. Those highly oxidized $\mathrm{Cys}-\mathrm{SO}_{2} \mathrm{H}$ and $\mathrm{Cys}-\mathrm{SO}_{3} \mathrm{H}$ residues, which are unaffected by the process of alkylation and reduction, will remain in these oxidized states. The various modifications of the PTPs are revealed by MALDI-MS analysis followed by MS/MS sequencing. residue in PTPs that had been exposed to ROS would be resistant to alkylation, whereas any active site Cys residues remaining in the reduced thiolate form would be carbamidomethylated. Upon reduction during SDS/PAGE, PTPs in which the active site $\mathrm{Cys}$ was irreversibly oxidized $\left(\mathrm{Cys}-\mathrm{SO}_{2} \mathrm{H}\right.$ and Cys- $\mathrm{SO}_{3} \mathrm{H}$ ) would remain oxidized. On the other hand, any PTPs in which the Cys was reversibly oxidized would be reduced to $\mathrm{Cys}^{-} \mathrm{S}^{-}$, allowing them to be distinguished from the original reduced form, which would have been converted to carbamidomethylated Cys (Cys-CAM) in the initial alkylation step. The gel was stained with Coomassie Blue, and the protein bands corresponding to the position of PTPs were subjected to MALDI-MS analysis followed by MS/MS sequencing.

To validate the MS-based strategy, we first established an in vitro model using purified PTP1B. The C-terminally-truncated, $37 \mathrm{kDa}$ human PTP1B protein was incubated with $\mathrm{H}_{2} \mathrm{O}_{2}$, followed by alkylation with iodoacetamide, and then subjected to reducing SDS/PAGE. We noticed that, whereas the control untreated PTP1B ran as a $37 \mathrm{kDa}$ protein (Fig. 3A), following treatment with $100 \mu \mathrm{M} \mathrm{H}_{2} \mathrm{O}_{2}$, PTP1B was resolved into two forms (Fig. 3B). When $10 \mathrm{~mm}$ $\mathrm{H}_{2} \mathrm{O}_{2}$ was applied, we observed that the electrophoretic mobility of all of the $\mathrm{PTP} 1 \mathrm{~B}$ was retarded to the $39 \mathrm{kDa}$ form (Fig. 3C). These protein bands were excised, digested in-gel with trypsin, and extracted peptides were profiled by MALDI-MS analysis. In general, $>50 \%$ of the protein sequence could be mapped, including all Cys-containing peptides (Fig. 4) and, in particular, the tryptic peptide containing the active site Cys (T28) could be clearly detected based on the exact molecular mass information. Under the experimental conditions employed, the free thiol on reduced Cys (Cys-SH) was expected to be carbamidomethylated (Cys-CAM). As expected, T28 from the iodoacetamide-reacted PTP1B sample generated predominantly a protonated molecular ion at $\mathrm{m} / \mathrm{z} 2232$ (Fig 3A), corresponding in mass to the expected peptide sequence carrying a carbamidomethylated Cys, indicating that the catalytic Cys of control PTP1B was predominantly in the active, reduced form. Importantly, a significant proportion of T28 from the lower $37 \mathrm{kDa}$ band derived from $100 \mu \mathrm{M} \mathrm{H}_{2} \mathrm{O}_{2}$-treated PTP1B (Fig 3B, lower panel) was found indeed to contain Cys-SH $(m / z$ 2175), in addition to Cys-CAM $(\mathrm{m} / z$ 2232), thus reflecting the appearance of the reversibly oxidized form of $\mathrm{PTP} 1 \mathrm{~B}$ in response to $\mathrm{H}_{2} \mathrm{O}_{2}$ treatment. MALDI-MS mapping revealed that the catalytic Cys in peptide T28 from the upper $39 \mathrm{kDa}$ band was primarily irreversibly oxidized. The 

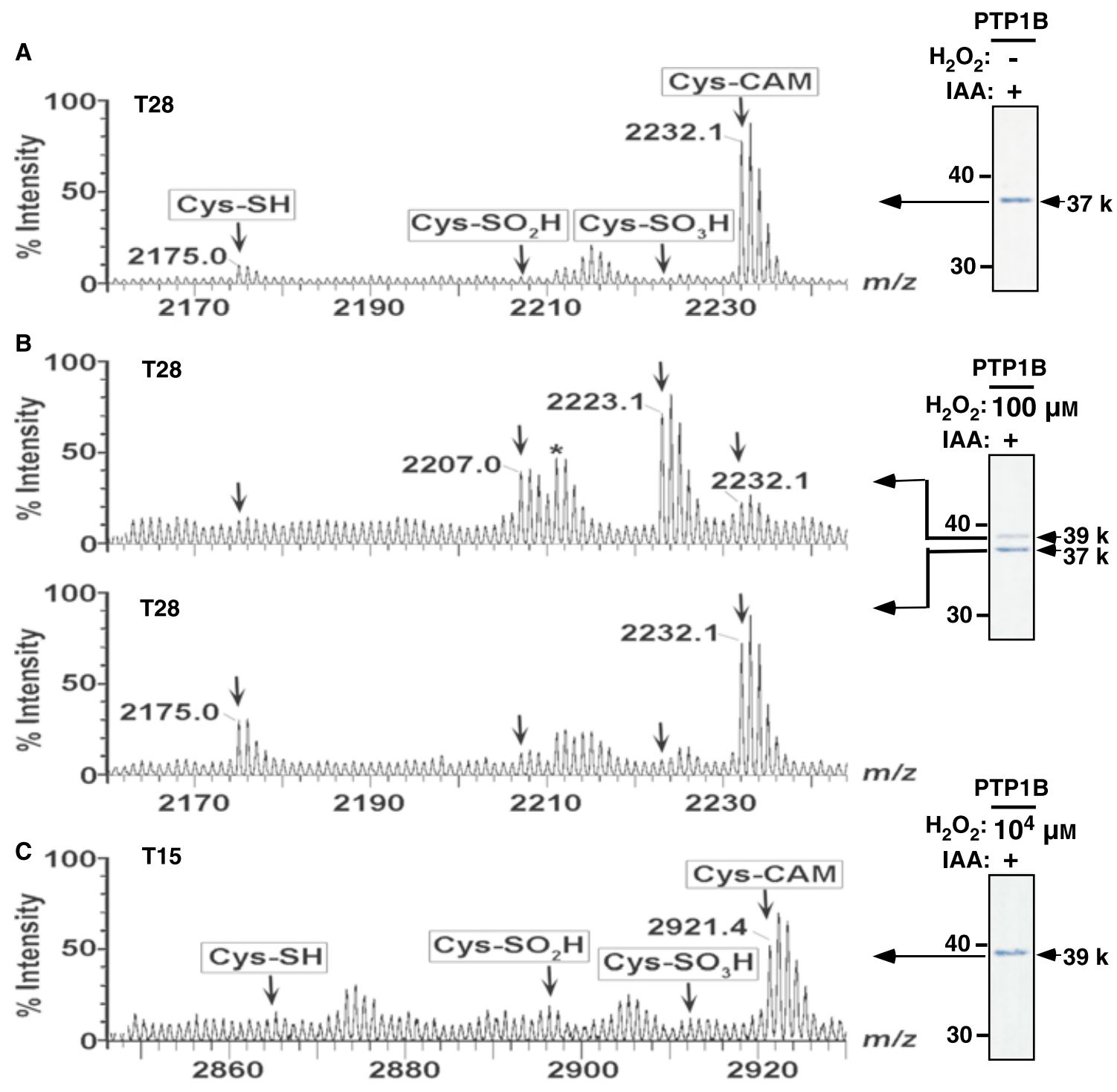

IAA: +

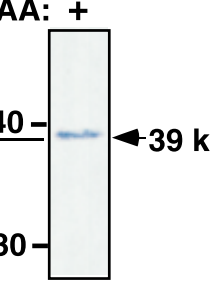

Fig. 3. Treatment of recombinant PTP1B with $\mathrm{H}_{2} \mathrm{O}_{2}$ induces oxidative modifications of its catalytic Cys residue. The recombinant $37 \mathrm{kDa}$ PTP1B was reacted with various concentrations of $\mathrm{H}_{2} \mathrm{O}_{2}$ at room temperature for 10 min. Following the addition of catalase, samples were incubated with iodoacetamide $(100 \mathrm{~mm})$ to alkylate reduced Cys residues in PTP1B. An aliquot of $1 \mu \mathrm{g}$ PTP1B per lane was subjected to reducing SDS/PAGE for Coomassie Blue staining. As indicated by arrowheads beside the gel images, PTP1B that had been reacted with $100 \mu \mathrm{M} \mathrm{H}_{2} \mathrm{O}_{2}$ (B) was resolved into 39 and $37 \mathrm{kDa}$ species, whereas $10 \mathrm{~mm} \mathrm{H}_{2} \mathrm{O}_{2}$-treated PTP1B showed only the $39 \mathrm{kDa}$ band (C). The forms of PTP1B before (A) and after treatment with $100 \mu \mathrm{M}(\mathrm{B})$ or $10 \mathrm{mM} \mathrm{H}_{2} \mathrm{O}_{2}$ (C) were resolved by SDS/PAGE and subjected to in-gel digestion for MALDI-MS mapping of tryptic peptides. The catalytic Cys215 that is susceptible to oxidation was carried on tryptic peptide T28 $(A, B)$, giving the $[M+H]^{+}$signals at $\mathrm{m} / z$ 2175, 2207, 2223 and 2232 (accurate monoisotopic mass), corresponding respectively to the reduced $(-\mathrm{SH})$, sulfinic acid $\left(-\mathrm{SO}_{2} \mathrm{H}\right)$, sulfonic acid $\left(-\mathrm{SO}_{3} \mathrm{H}\right)$, and carbamidomethylated $(-\mathrm{CAM})$ forms, as indicated in $(A)$. (C) The MS region where another Cys-containing tryptic peptide (T15) was detected primarily in the carbamidomethylated form $(\mathrm{m} / z$ at 2921$)$ is shown. The peak at $\mathrm{m} / \mathrm{z} 2211$, marked with an asterisk, corresponds to a peptide derived from autodigested trypsin.

two molecular ion signals detected at $\mathrm{m} / \mathrm{z} 2207$ and 2223 could be assigned to $\mathrm{T} 28$ carrying a $\mathrm{Cys}-\mathrm{SO}_{2} \mathrm{H}$ and a Cys- $\mathrm{SO}_{3} \mathrm{H}$, respectively (Fig 3B, upper panel). At a higher $\mathrm{H}_{2} \mathrm{O}_{2}$ concentration $(10 \mathrm{mM})$, we observed only the upper $39 \mathrm{kDa}$ band, which gave the same irreversibly oxidized T28 peptides upon tryptic digestion (data not shown). It is important to note that oxidation appeared to be confined specifically to the invariant catalytic Cys, whereas the other Cys residues in PTP1B remained unaffected and thus were detected mainly in a carbamidomethylated form, as illustrated by Cys92 in peptide T15 (Fig 3C). Our 


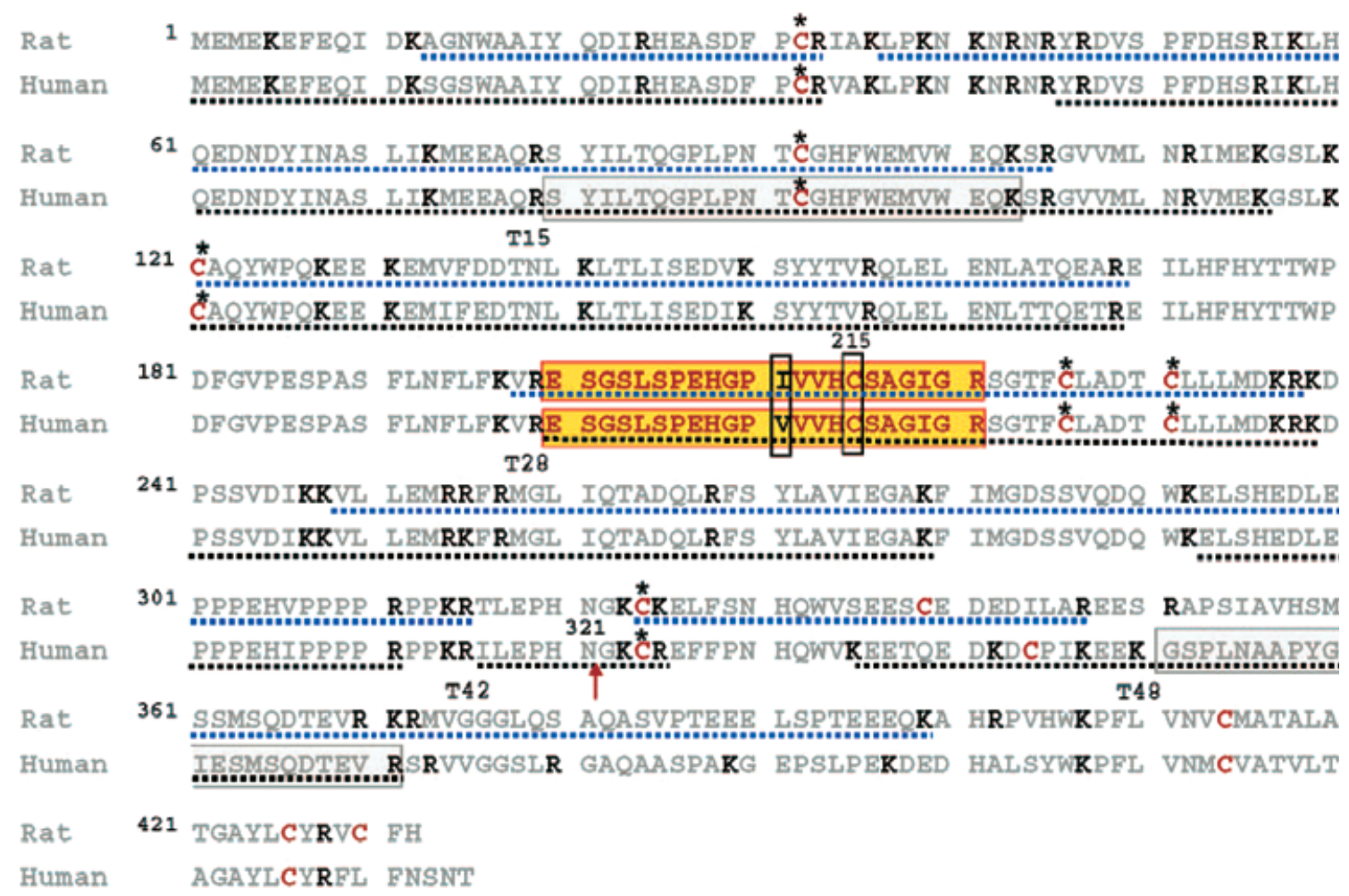

Fig. 4. MALDI-MS and MS/MS identification of peptides and Cys residue modifications of human and rat PTP1B. The tryptic peptide sequences in gray are delimited by $\mathrm{K}$ and $\mathrm{R}$ residues in black and named sequentially from the $\mathrm{N}$-terminus. Those detected by MALDI-MS mapping are underscored with a dotted line whereas the catalytic Cys-containing peptide (T28) is boxed and shaded. All other Cys residues marked with an asterisk were successfully detected by MALDI-MS mapping and shown not to be susceptible to oxidation. The recombinant human PTP1B used in experiments shown in Fig. 3 was C-terminally-truncated relative to the endogenous form. It terminated at Asn321 (vertical arrowhead) and thus did not give rise to the tryptic peptide T42, which was only generated from full-length PTP1B. The T28 peptide of rat PTP1B differs from the human sequence by one amino acid residue, as boxed. The Arg-C protease does not cleave efficiently at Lys, thus producing longer Lys-containing peptides that span tryptic cleavage sites; however, this specificity is not absolute. A tryptic peptide T48 from the C-terminal segment of the native form of PTP1B overlaps in mass with the triply oxidized $\left(\mathrm{Cys}-\mathrm{SO}_{3} \mathrm{H}\right) \mathrm{T} 28$ peptide and was largely removed by using Arg-C instead of tryptic digestion as described. However, a small amount of T48 was still produced, as demonstrated by MS/MS sequencing (Fig. 9), indicating a small degree of unintended cleavage at Lys by the Arg-C protease.

data thus demonstrate the feasibility of MS-based analysis to identify various oxidized forms of the Cys residue at the active site of a given PTP and highlight the fact that PTP oxidation is restricted to the active site Cys residue.

\section{MS-based analyses identified reversible and irreversible oxidation of catalytic Cys of endogenous PTP1B in HepG2 and A431 cells}

In the next phase of the study, we sought direct evidence of oxidation-dependent modification of the active site Cys residue of endogenous PTPs in cells. Initially, we conducted a pilot experiment to validate the MS-based strategy for detecting the oxidation status of PTP1B (Fig. 2). Accordingly, we focused our attention on normal Rat-1 fibroblasts, which generated low to undetectable levels of ROS in the absence of serum (Fig. 5A), suggesting that endogenous PTPs expressed in Rat-1 cells would presumably be in the reduced state (Fig. 5B). These experiments in Rat-1 cells should also serve as an ideal model to examine the effectiveness of our cell lysis procedure in minimizing post-lysis oxidation, a critical prerequisite to ensure the accuracy of MS-based analysis of the redox status of endogenous PTPs. PTP1B, which was immunoprecipitated from Rat-1 lysates in the presence of iodoacetamide, was identified as a $50 \mathrm{kDa}$ protein band by SDS/PAGE (Fig. 5C). The band was excised from the gel, digested with trypsin, and subjected to MALDI-MS analysis, which demonstrated that the catalytic Cys residue was in the carbamidomethylated form (Fig. 5D), reflecting its original reduced state in cells. Importantly, we did not observe reversibly or irreversibly oxidized 
A

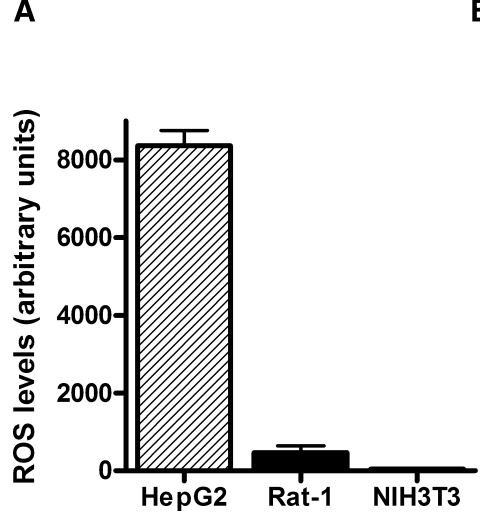$$
\text { D }
$$

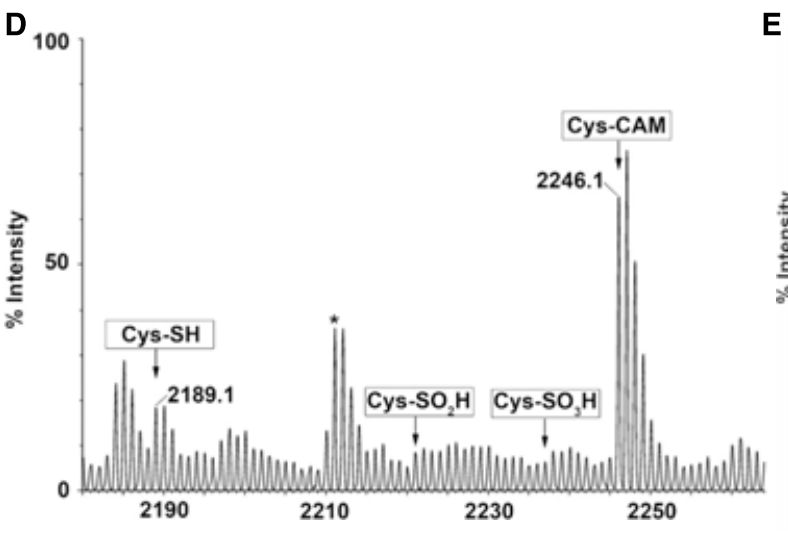

B Cell: $\mathbf{R} \mathbf{N} \mathbf{R}$
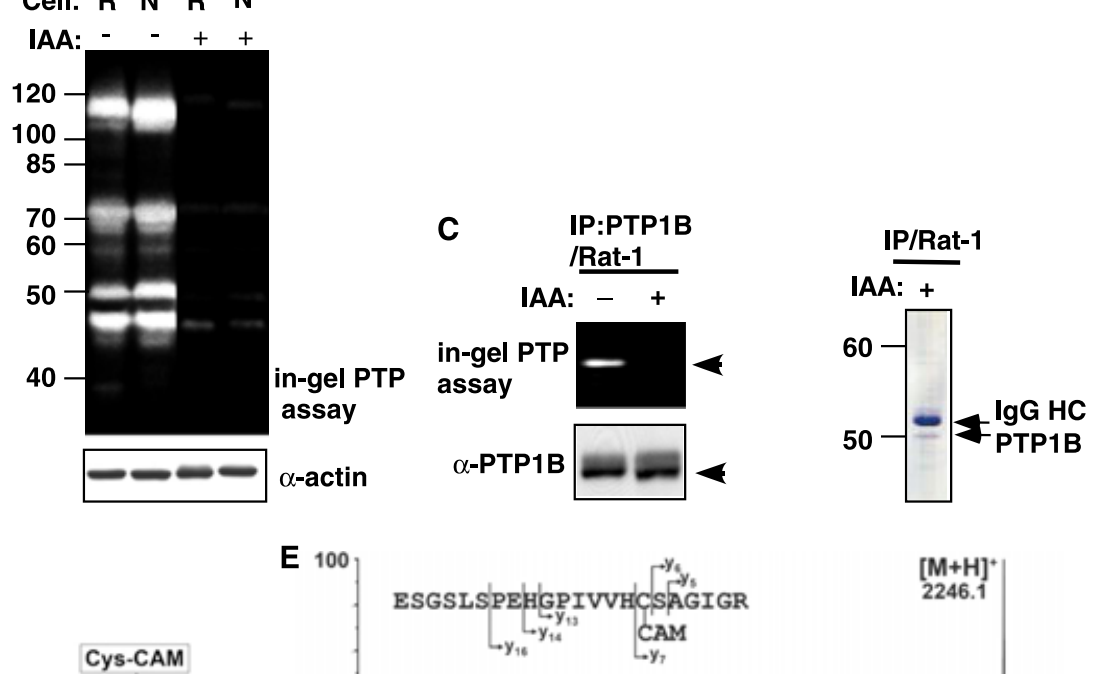

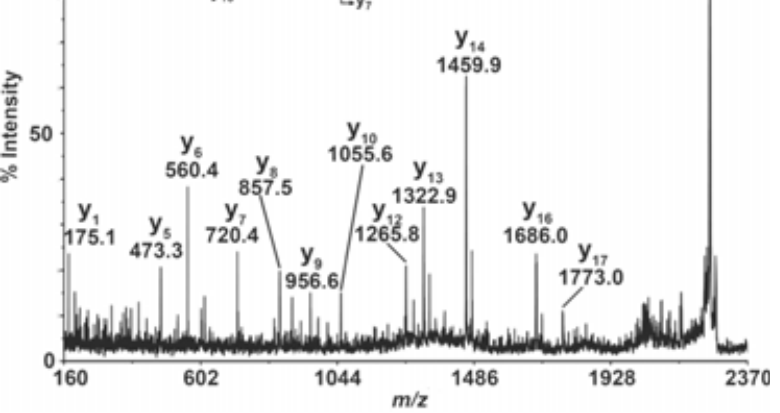

Fig. 5. PTP1B expressed in normal Rat-1 fibroblasts, which produce a low level of ROS, is mostly in the reduced and active form. (A) HepG2, Rat-1 and NIH3T3 cells were incubated with Amplex Red for $60 \mathrm{~min}$, and the levels of cellular ROS production were measured according to the procedure described in the Experimental procedures. (B) Rat-1 (R) and NIH3T3 (N) cells were serum starved for $16 \mathrm{~h}$ prior to lysis in the absence (-) or presence (+) of $100 \mathrm{~mm}$ iodoacetamide (IAA). An aliquot of lysate (25 $\mu \mathrm{g})$ was subjected to an in-gel phosphatase activity assay (upper panel) or to immunoblotting with anti-actin serum (lower panel). (C) Serum-starved Rat-1 cells were harvested in the absence (-) or presence (+) of 100 mM iodoacetamide. Endogenous PTP1B was immunoprecipitated with antibody FG6 followed by ingel phosphatase activity assay (upper left panel) or immunoblotting with anti-PTP1B serum (lower left panel). The arrowhead indicates the position of endogenous PTP1B in an SDS/PAGE gel. An aliquot of immunocomplex obtained from iodoacetamide-treated lysate was subjected to SDS/PAGE, followed by Coomassie Blue staining (right panel). The position of PTP1B or IgG heavy chain (lgG HC) in an SDS/PAGE gel is indicated by an arrowhead. (D, E) MALDI-MS mapping (D) and MS/MS sequencing (E) of the active site Cys215-containing peptide T28 from endogenous PTP1B of serum starved Rat-1 cells. The PTP1B band shown in Coomassie Blue staining (C) was excised from the gel for analysis. In (D), the expected peaks for the redox variants of the T28 peptide are indicated. In (E), the characteristic mass difference of $160 u$ between $y_{6}$ and $y_{7}$ unambiguously defined a carbamidomethylated Cys residue. The rest of the $y$ ion series defined the overall sequence of T28, as illustrated schematically. The asterisk in (D) denotes a peptide derived from autodigested trypsin. On the basis of these data, we conclude that the endogenous PTP1B expressed in Rat-1 fibroblasts is mostly in the reduced and active form (B-E). This is in accordance with a very low level of spontaneous ROS production by Rat-1 cells (A).

derivatives of the Cys residue in the immunoprecipitates, consistent with the low level of constitutive ROS production by Rat-1 cells (Fig. 5A). The identity of the peptide was confirmed by MS/MS sequencing (Fig. 5E). These data demonstrate that this MS-based strategy can be used to detect the peptide containing the active site Cys from endogenous PTP1B that had been immunoprecipitated from cell lysates. Following the same experimental procedures, we investigated whether ROS produced in human cancer cells led to oxidation of the catalytic Cys residue of PTP1B.
Endogenous PTP1B was immunoprecipitated from HepG2 and A431 cells, which had been cultured in serum-free medium without additional stimuli, then lysed in the presence of iodoacetamide under anaerobic conditions. Immunocomplexes were subjected to SDS/ PAGE in reducing conditions for either Coomassie Blue staining or in-gel phosphatase activity assay. From the immunoprecipitates, PTP1B was resolved into two species, of $\sim 50$ and $52 \mathrm{kDa}$, by SDS-PAGE (Figs 6A and 7A). The $50 \mathrm{kDa}$ PTP1B (lower band) was active, as revealed by the in-gel assay, whereas no 
A
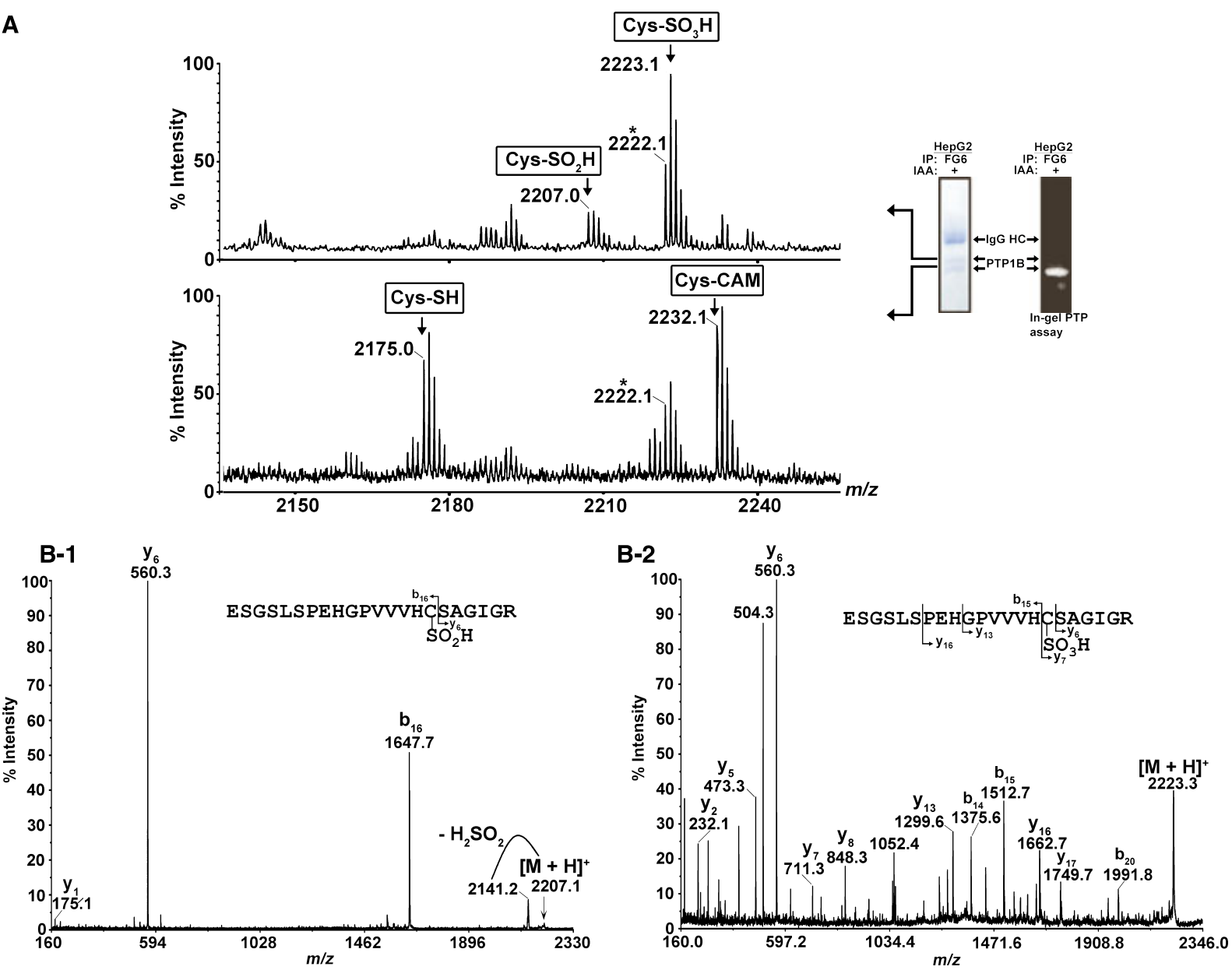

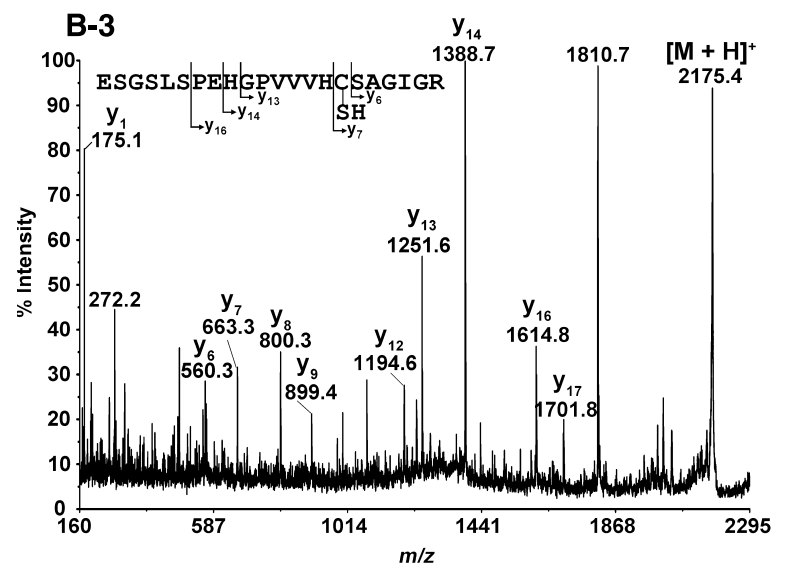

activity was measured in the $52 \mathrm{kDa}$ species (higher band) (Figs 6A and 7A). The 50 and $52 \mathrm{kDa}$ protein bands were excised from the gel and subjected to in-gel Arg-C digestion. The choice of Arg-C digestion in favor of trypsin was to reduce the intensity of a tryptic peptide, T48, that would otherwise interfere with identification of the T28 peptide containing the catalytic

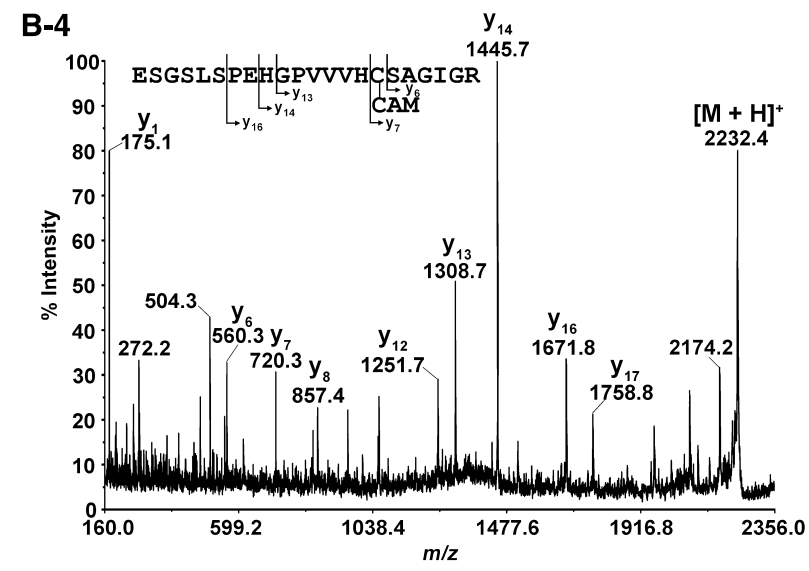

Cys in a highly oxidized state $\left(\mathrm{SO}_{3} \mathrm{H}\right)$ at $\mathrm{m} / z$ 2223, with the two differing by only 1 mass unit. The peptide mass mapping was then carried out by MALDIMS/MS, which clearly identified that both 50 and $52 \mathrm{kDa}$ protein bands were human PTP1B, as revealed by the MASCOT search engine (sequences are summarized in Fig. 4). It is interesting to note that, although 
Fig. 6. ROS produced by HepG2 cells induce constitutive oxidation and inactivation of endogenous PTP1B. HepG2 cells were serum-starved for $16 \mathrm{~h}$ prior to lysis in the presence of $100 \mathrm{~mm}$ iodoacetamide. The endogenous PTP1B was immunoprecipitated with anti-PTP1B serum FG6. After reducing SDS/PAGE, staining with Coomassie Blue revealed that PTP1B in the immunocomplex segregated into two bands ( 50 and $52 \mathrm{kDa}$; arrowheads in A), which were analyzed by in-gel phosphatase activity assay and MALDI-MS mapping (A), as well by MS/MS sequencing (B). The relevant region of the mass spectra for the derived Arg-C peptides is shown in the upper and lower panels respectively, as indicated in (A). The expected occurrence of the molecular ion signals for the redox variants of T28 is annotated and each was further subjected to MALDI-TOF/TOF MS/MS analysis as shown in (B) for the Cys-SO ${ }_{2} \mathrm{H}$ (B-1, from $\sim 52 \mathrm{kDa}$ band), Cys-SO $\mathrm{H}_{3}(\mathrm{~B}-2$, from $\sim 52 \mathrm{kDa}$ band), Cys-SH (B-3, from $\sim 50 \mathrm{kDa}$ band), and Cys-CAM (B-4, from $\sim 50 \mathrm{kDa}$ band) forms, respectively. In each case, a common $y_{6}$ ion could be detected at $m / z 560$, followed by different $y_{7}$ ions, the $m / z$ values of which essentially define the modification state of the Cys. This is further supported by other higher $y$ ions detected, as annotated. The peak at $\mathrm{m} / \mathrm{z} 2222$, marked with an asterisk in (A), corresponds to a peptide derived from Arg-C-digested T48. In the case of $\mathrm{T} 28$ carrying $\mathrm{Cys}-\mathrm{SO}_{3} \mathrm{H}$ from the upper band (B-2), the MS/MS spectrum is a composite of that contributed by T28 and T48, the respective parent ions differ only by 1 mass unit and were not resolved for MS/MS analysis. Only the daughter ions from T48 could be observed in the MS/MS spectrum of the parent at $\mathrm{m} / \mathrm{z} 2222$ from the $\sim 50 \mathrm{kDa}$ lower band, indicating that an irreversibly oxidized form of PTP1B was not found.

the mobility of proteins in SDS/PAGE gels may be affected by phosphorylation, as documented in numerous studies, we did not observe any detectable level of $\mathrm{Ser} / \mathrm{Thr} / \mathrm{Tyr}$ phosphorylation in both forms of PTP1B according to MS-based analyses. Indeed, the MALDIMS data demonstrated that the Arg-C digests from the upper band comprised both irreversibly oxidized forms, as the two molecular ion signals detected at $m / z 2207$ and 2223 could be assigned to T28 carrying a Cys- $\mathrm{SO}_{2} \mathrm{H}$ and $\mathrm{Cys}-\mathrm{SO}_{3} \mathrm{H}$, respectively (Figs $6 \mathrm{~A}$ and $7 \mathrm{~A})$. This is consistent with the observation that this form of PTP1B did not display activity in the in-gel phosphatase activity assay (Figs 6A and 7A), and was detected by immunoblotting using an antibody specifically recognizing PTPs whose catalytic Cys was in the sulfonic acid modification (Fig. 8). By contrast, the lower band afforded signals of the Cys-SH and CysCAM forms at $\mathrm{m} / z 2175$ and 2232 (Figs 6A and 7A), reflecting the presence of the reversibly oxidized forms and reduced forms of endogenous PTP1B, respectively. Each of the four was further analyzed by MALDIMS/MS, which afforded unambiguous confirmation of both peptide sequence and the site specific Cys-modifications through the mass interval defined by the $y_{7}$ and $y_{6}$ ions (Figs 6B and 7B). It should be noted that the peak at $\mathrm{m} / z 2223$ from the lower band (Figs 6A and $7 \mathrm{~A}$ ) was not derived from the $\mathrm{Cys}-\mathrm{SO}_{3} \mathrm{H}$ form of T28 peptide. MS/MS analysis confirmed that this signal corresponds to the isotope peak of the aforementioned T48 peptide (monoisotopic at $\mathrm{m} / \mathrm{z} 2222$ ), a result of a small degree of Lys-cleavage induced by the Arg-C digestion (Fig. 9). The results obtained from the MALDI-MS analysis also demonstrate that other Cys residues in the immunoprecipitated $50 \mathrm{kDa}$ or $52 \mathrm{kDa}$ PTP1B (Fig. 4) were completely carbamidomethylated, indicating their reduced status. Our data thus provide unambiguous evidence demonstrating that the catalytic Cys residue of endogenous PTP1B expressed in HepG2 and A431 cells was oxidized by intrinsic ROS and that this Cys residue was modified selectively.

\section{A substantial fraction of endogenous PTP1B is constitutively oxidized in HepG2 and A431 cells}

We wished to quantitate the relative proportion of the oxidized forms of endogenous PTP1B in cells. Densitometric analyses in the Coomassie Blue-stained images revealed that the intrinsic oxidative stress in HepG2 and A431 cells drove $43 \%$ and $38 \%$ of endogenous PTP1B, respectively, to an irreversibly oxidized, $\sim 52 \mathrm{kDa}$ form (Fig. 10A). The protein band at the $\sim 50 \mathrm{kDa}$ position, which comprised the remaining $57 \%$ (HepG2) or $62 \%$ (A431) of PTP1B (Fig. 10A), was subjected to further analysis to determine the relative quantity of the reversibly oxidized and reduced forms of the enzyme. For this purpose, we established a calibration curve. A synthetic peptide with the sequence of the T28 peptide of human PTP1B was either left untreated or reacted with excess iodoacetamide for complete alkylation of the Cys residue. The free sulfydryl (Cys-SH) and carbamidomethylated (Cys-CAM) peptides were mixed in various molar ratios prior to MALDI-MS analysis. In the analysis of each peptide mixture, we calculated an intensity ratio between the MS peak $m / z 2175$ (T28-Cys-SH) and the peak $m / z 2232$ (T28-Cys-CAM). A calibration curve of the MS intensity ratio over the molar ratio [T28-Cys$\mathrm{SH}]$ to [T28-Cys-SCAM] was constructed. As shown in Fig. 10B, within the range in the present study, the molar ratios of free and alkylated T28 peptide showed a perfect linear relationship with the corresponding MS intensity ratios. Thus, alkylation of the peptide did not affect its ionization during MS. Therefore, on the basis of such a calibration curve, we calculated the relative proportion of reversibly oxidized and reduced forms of endogenous PTP1B. The intensity ratio (peak 
A
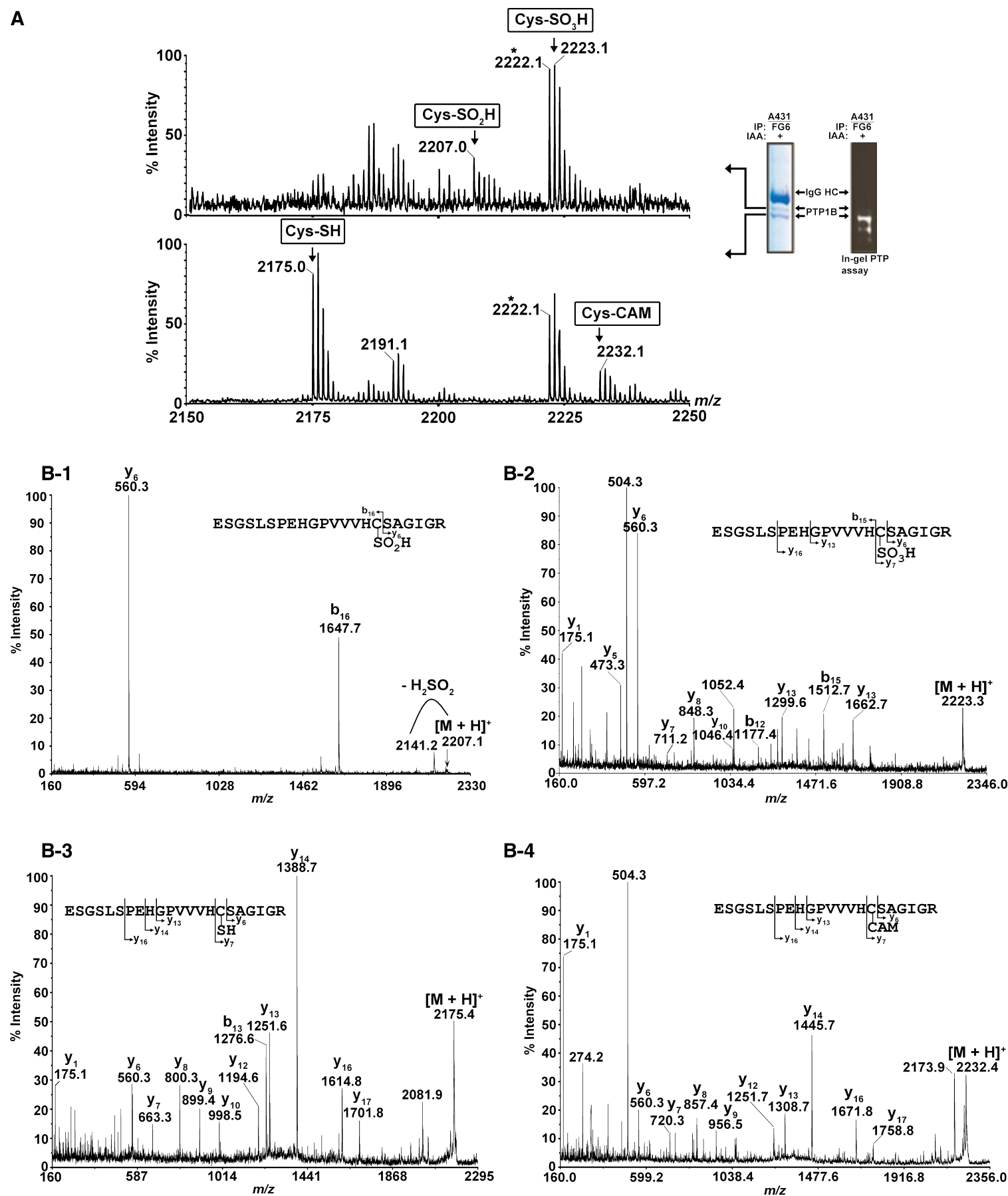

B-4

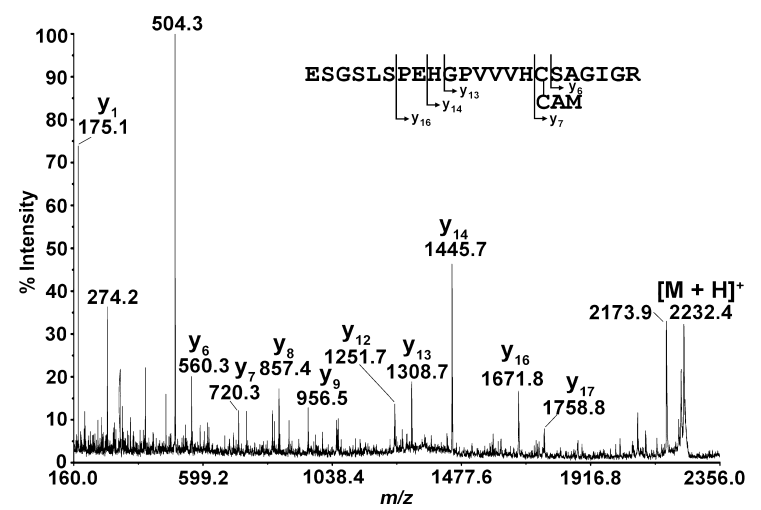

Fig. 7. ROS produced by A431 cells induce constitutive oxidation and inactivation of endogenous PTP1B. The experimental details are described in the legend of Fig. 6. Briefly, A431 cells were serum-starved prior to lysis in the presence of iodoacetamide. The immunoprecipitated PTP1B was subjected to reducing SDS/PAGE followed by Coomassie Blue staining. As in HepG2 cells (Fig. 6), the FG6-precipitated immune complex of PTP1B from A431 cells segregated into two bands ( 50 and $52 \mathrm{kDa}$; arrowheads in $\mathrm{A})$. The relevant region of the mass spectra for the derived Arg-C peptides is shown in the upper and lower panels respectively, as indicated in (A). The expected occurrence of the molecular ion signals for the redox variants of T28 is annotated and each was further subjected to MALDI-TOF/TOF MS/MS analysis as shown in (B) for the Cys- $\mathrm{SO}_{2} \mathrm{H}$ (B-1, from $\sim 52 \mathrm{kDa}$ band), Cys-SO ${ }_{3} \mathrm{H}$ (B-2, from $\sim 52 \mathrm{kDa}$ band), Cys-SH (B-3, from $\sim 50 \mathrm{kDa}$ band), and Cys-CAM (B-4, from $\sim 50 \mathrm{kDa}$ band) forms, respectively. The peak at $m / z 2222$, marked with an asterisk in (A), corresponds to a peptide derived from Arg-C-digested T48. 
A
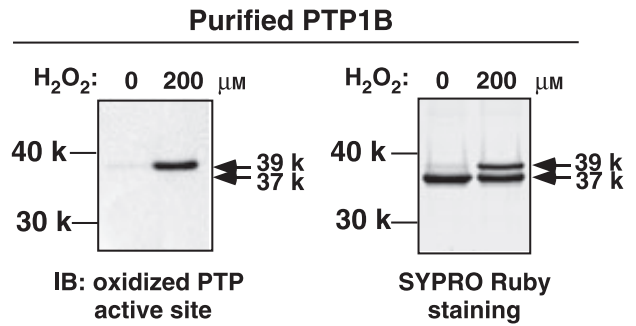

B

A431 cells/IP: PTP1B (AF1366)
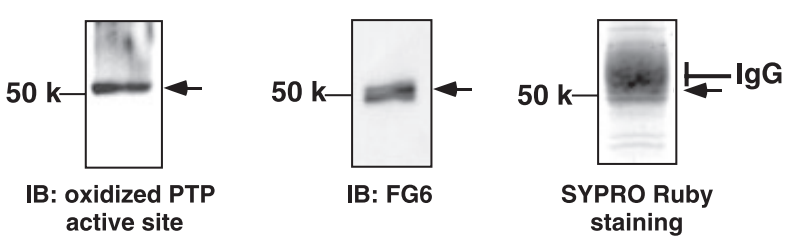

Fig. 8. Immunoblotting analysis of highly oxidized PTP1B. Recombinant $37 \mathrm{kDa}$ PTP1B, either untreated, or reacted with $\mathrm{H}_{2} \mathrm{O}_{2}$, was subjected to reducing SDS/PAGE for immunoblotting or Coomassie Blue staining. As indicated by arrowheads beside the gel image (right panel), PTP1B that had been treated with $\mathrm{H}_{2} \mathrm{O}_{2}$ was resolved into 39 and $37 \mathrm{kDa}$ species. Immunoblotting with mouse anti-(oxidized PTP active site) serum demonstrated that only the $39 \mathrm{kDa}$ band, which appeared in $\mathrm{H}_{2} \mathrm{O}_{2}$-treated PTP1B, was irreversibly oxidized, consistent with our MS-based analysis. (B) PTP1B was immunoprecipitated from serum-starved A431 cells with rabbit antiPTP1B serum, then immunoblotted with anti-(oxidized PTP active site) serum or mouse anti-PTP1B serum FG6. An aliquot of the immunocomplex was also applied to SDS/PAGE, followed by SYPRO Ruby staining (Sigma-Aldrich). The arrowheads indicate the position of irreversibly oxidized species (left panel), which is located in the slower migrating band in the immunoblot with FG6 antibody (right panel).

$m / z 2175$ over peak $m / z$ 2232), obtained from the MS analysis of the $50 \mathrm{kDa}$ protein band in immunocomplexes (Figs 6A and 7A), was used for the calculation. The results indicated that $\sim 25 \%$ or $49 \%$ of total PTP1B protein immunoprecipitated from HepG2 or A431 cells, respectively, was in the reversibly oxidized form (Fig. 10A). Our results also demonstrate that the reduced, and thereby active, form of endogenous PTP1B represented a relatively small proportion of total PTP1B (32\% and $13 \%$ in HepG2 and A431 cells, respectively).

\section{Suppression of ROS production leads to decreased PTP oxidation, inhibition of tyrosine phosphorylation and decreased anchorage- independent growth in HepG2 cells}

It has been shown that Nox enzymes generate ROS in a variety of cell types [6,7], and that accumulation of
ROS may contribute to cell transformation [24-26]. On the basis of these observations, we examined whether the activation of endogenous Nox enzymes contributed to PTP oxidation in HepG2 and A431 cells. To test this hypothesis, we examined the effect of diphenyleniodonium (DPI), a conventionally used inhibitor of Nox enzymes [27]. As shown in Fig. 11A, the addition of DPI significantly suppressed the level of ROS generated by HepG2 and A431 cells. Interestingly, the inhibition of $\mathrm{H}_{2} \mathrm{O}_{2}$ production in response to DPI treatment attenuated the oxidation of cellular PTPs, as indicated by decreased signals from the 115, 50 and $45 \mathrm{kDa}$ phosphatases in the in-gel assay (Fig. 11B, arrowheads).

When we assayed endogenous PTP1B specifically in immunoprecipitates from HepG2 cells grown in serumfree medium in the absence or presence of DPI, we observed that treatment with DPI led to a decrease in the reversible oxidation of the $50 \mathrm{kDa}$ PTP1B protein (Fig. 12A). In light of this DPI-mediated reactivation of PTP1B, as well as other endogenous PTPs (Fig. 11B), we assessed the overall status of protein tyrosine phosphorylation in HepG2 cells under these conditions. As shown in Fig. 12B, the level of phosphotyrosine in multiple cellular proteins, in the range 80-200 kDa, and a low molecular weight protein of $\sim 30 \mathrm{kDa}$, were significantly reduced in response to DPI treatment. Our data suggest that, in response to the suppression of ROS production, decreased PTP oxidation resulted in increased PTP activity, and therefore increased dephosphorylation of tyrosine residues in cellular proteins. It has been well documented that protein tyrosine phosphorylation is pivotal to the control of mitogenic signaling and cell transformation. Therefore, we explored the effect of DPI-dependent inhibition of tyrosine phosphorylation on the regulation of anchorage-independent growth of HepG2 cells. As shown in Fig. 12C, HepG2 cells formed large colonies in the soft agar medium, as expected for transformed cells. Interestingly, in the presence of DPI, the number of large HepG2 cell colonies was significantly decreased (Fig. 12C). Collectively, these data indicate that the constitutive production of ROS is a prerequisite for inactivation of endogenous PTPs, which may in turn promote protein tyrosine phosphorylation and contribute to the transformed phenotype of HepG2 cells.

\section{Discussion}

Initially, ROS were viewed only as a harmful by-product of life in an aerobic environment, leading to deleterious effects, such as DNA damage, and ultimately 


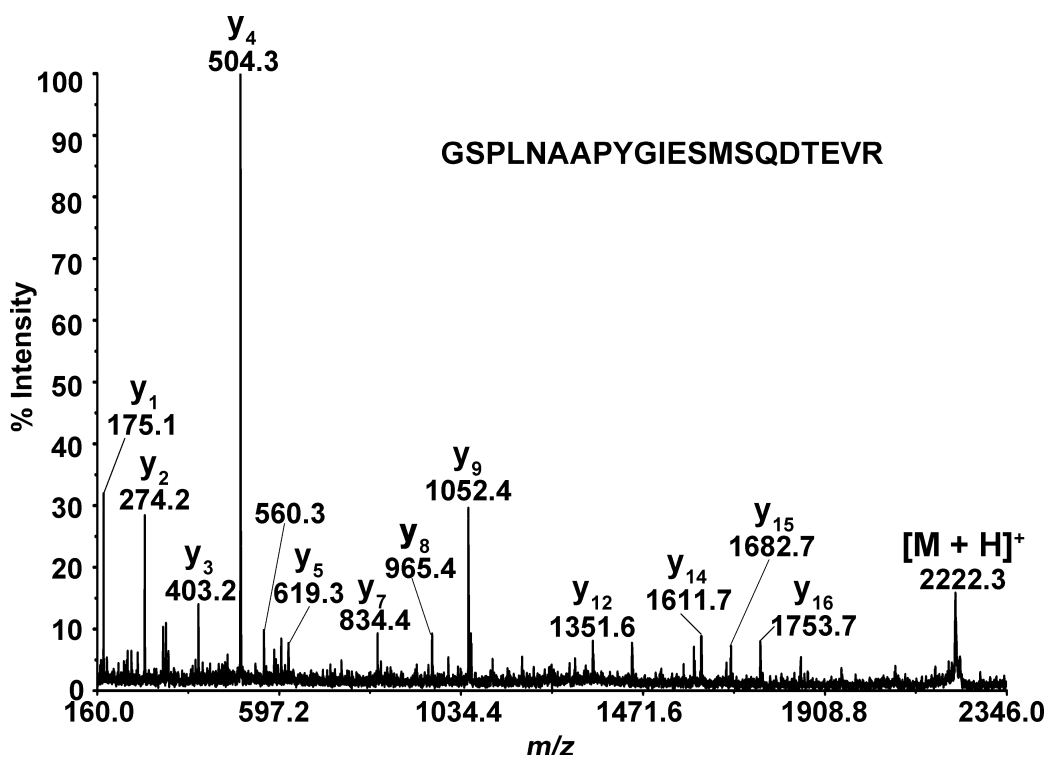

Fig. 9. MS/MS analysis of the peptide with $\mathrm{m} / \mathrm{z}$ 2222. The peptide peak at $\mathrm{m} / \mathrm{z} 2222$ in the MALDI-MS spectrum of Arg-C-digested $50 \mathrm{kDa}$ PTP1B precipitated from HepG2 cells (Fig. 6A, lower panel) was subjected to MS/MS sequencing. The result demonstrated that only the fragment ions from peptide T48 were observed, presumably generated by the non-specific cleavage of Arg-C-mediated hydrolysis. Fragment ions that would be derived from the sulfonic acid-modified peptide T28 ( $\mathrm{m} / \mathrm{z} 2223)$ were not detected and, therefore, this indicates that the $50 \mathrm{kDa}$ protein band does not contain the irreversibly oxidized form of PTP1B. such conditions as cell transformation, neurodegeneration and aging. The first biological role of ROS to be identified was attributed to the controlled production of a burst of oxidants generated by phagocytic leukocytes in the innate immune response to infection [7]. More recently, evidence has accumulated indicating that low concentrations of ROS can function as regulatory molecules in tyrosine phosphorylation-dependent mitogenic signaling pathways [28,29]. It is well documented that various extracellular stimuli (e.g. peptide growth factors, hormones, cytokines and agonists of G-protein coupled receptors) induce transiently increased levels of cellular ROS [8,15,17-19,21,30,31]. Pre-incubation of cells with anti-oxidants or ectopic expression of enzymes that degrade $\mathrm{H}_{2} \mathrm{O}_{2}$ inhibits ligand-induced tyrosine phosphorylation-dependent signaling responses $[15,17-19,21]$, suggesting that oxidation-dependent regulation of signaling molecules is critical for the control of cellular homeostasis. In the context of phosphotyrosine signaling, it appears, for the most part, that protein tyrosine kinases are not a direct target of ROS [32], although there have been reports of the regulation of Src by oxidation of critical Cys residues [33]. By contrast, a large number of studies have highlighted that PTPs may be oxidation sensors, due to the low $\mathrm{pK} \alpha$ character of the invariant active site Cys residue that is highly susceptible to oxidation with concomitant enzyme inactivation $[10,11,34]$.

In response to elevated concentrations of ROS, the active site Cys residue in PTPs may be oxidized sequentially to sulfenic acid (cyclic sulfenamide), sulfinic acid or sulfonic acid derivatives $[13,35]$. To test whether PTPs are indeed regulated by cellular ROS, several experimental approaches have been developed. For example, measurement of enzymatic activity in total lysates showed a significant loss of overall PTP activity in cells stimulated with $\mathrm{H}_{2} \mathrm{O}_{2}$ [36,37] or in response to physiological ligands that triggered intrinsic ROS production [17]. These results suggest that endogenous PTPs might be regulated in a redox-dependent manner. Moreover, susceptibility to labeling with an alkylating agent, which reacts with the catalytic Cys of reduced PTPs but not with oxidized PTPs, was used to measure the extent to which PTPs become oxidized, as in the case of epidermal growth factor-induced oxidation of PTP1B [38] or $\mathrm{T}$ cell antigen receptorinduced oxidation of the $\mathrm{SH} 2$ domain-containing phosphatase SHP-2 [39]. In addition, the differential sensitivity of oxidized and reduced PTPs to iodoacetic acid was also used as the basis for a modified in-gel phosphatase activity assay. For this assay, only the non-alkylated, reversibly oxidized PTPs have the potential to refold in the gel in the presence of dithiothreitol and recover their activity, which is visualized by dephosphorylation of a ${ }^{32} \mathrm{P}$-labeled substrate contained within the gel [40]. The application of this method revealed that SHP-2 was reversibly oxidized in Rat-1 cells exposed to platelet-derived growth factor [19] and that two non-receptor PTPs, namely PTP1B and TC-PTP, were susceptible to reversible oxidation in insulin-stimulated cells [18]. In addition, the result of in-gel phosphatase activity assays demonstrated that several PTPs were reversibly oxidized by irradiation of A431 cells with UV light [41]. Overall, the oxidation of each of the different PTP sub-types, receptor-like PTPs 


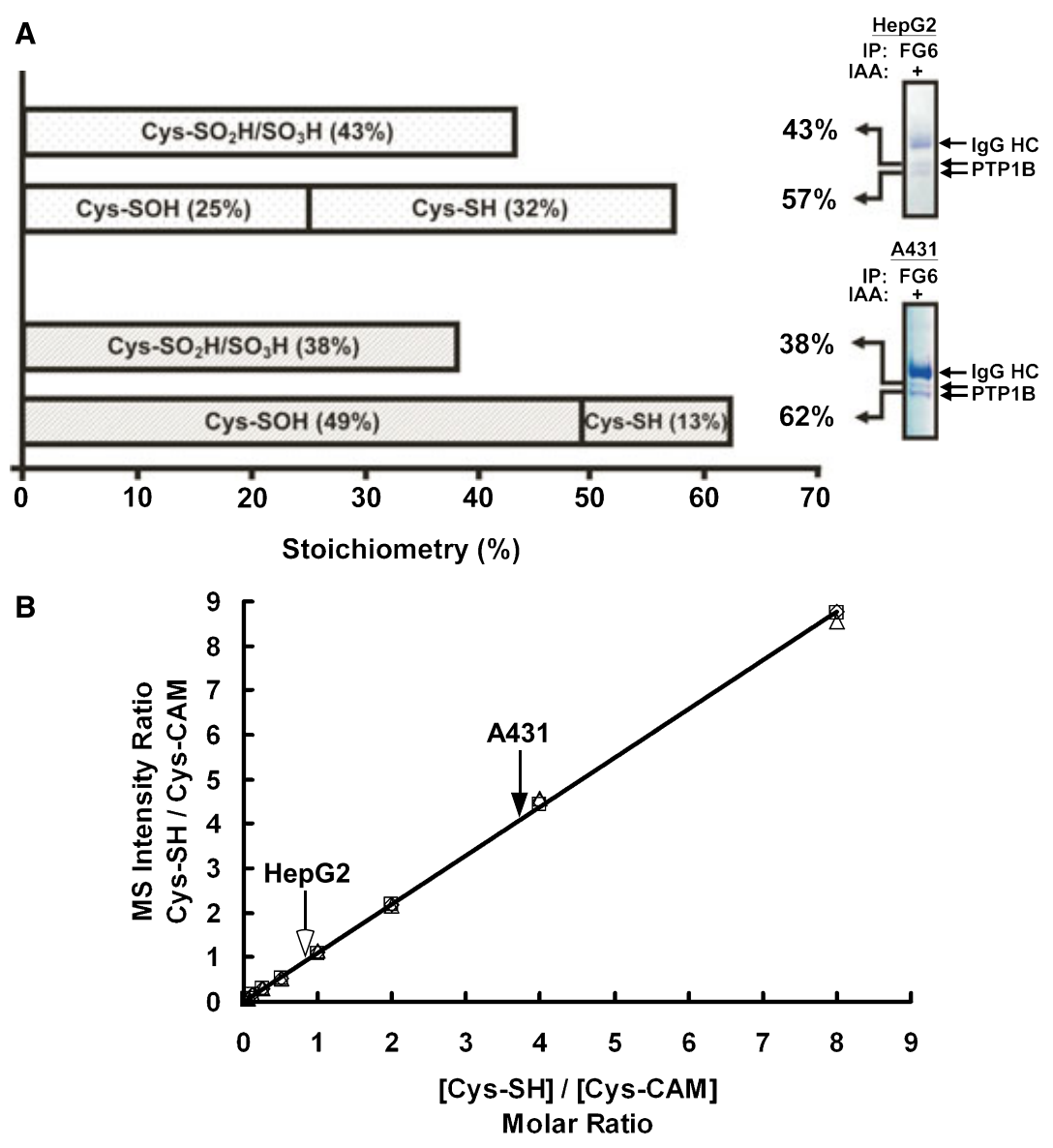

Fig. 10. Determination of relative ratio of various oxidized forms and reduced form of PTP1B in HepG2 and A431 cells. (A) Densitometric analysis of the protein bands obtained by Coomassie Blue staining afforded an estimate of the relative amount of the 52 (higher band) and $50 \mathrm{kDa}$ (lower band) forms of PTP1B in FG6 immunocomplexes isolated from HepG2 and A431 cells, as described in Figs 6 and 7, respectively. The $52 \mathrm{kDa}$ protein, which represented $43 \%$ of the total population of PTP1B in HepG2 cells and $38 \%$ in A431 cells, consisted of PTP1B with irreversibly oxidized modifications of its catalytic Cys. The $50 \mathrm{kDa}$ protein was subjected to analysis that determined the relative proportion between reversibly oxidized form and reduced form of PTP1B in HepG2 and A431 cells. The calibration curve obtained in (B) was used to convert the ratio of MS intensity between T28-Cys-SH and T28-Cys-CAM (Figs 6A and 7A, lower panel) into the molar ratio between the reversibly oxidized and the reduced forms of endogenous PTP1B, respectively. (B) A peptide (designated by T28s) with the sequence of the T28 tryptic peptide of PTP1B was synthesized by a solid phase method and the purity (> 95\%) was confirmed via MALDI-TOF-MS and ESI-MS analysis (data not shown). In order to carbamidomethylate T28s, excess iodoacetamide (5 mM) was reacted with the peptide (1 $\mu \mathrm{M}$ ) at $37{ }^{\circ} \mathrm{C}$ for $1 \mathrm{~h}$. The standard solution was prepared by mixing the reduced (Cys-SH) and the carbamidomethylated (Cys-S-CAM) T28s in the molar ratios: $1: 0.125,1: 0.25,1: 0.5,1: 1,1: 2,1: 4$ and $1: 8$, as shown on the $x$-axis in the figure. All samples were subjected to MALDI-MS analysis. The peaks of $\mathrm{m} / z 2175$ and $\mathrm{m} / z 2232$ on the spectrum were quantitated for calculating the MS intensity ratio between Cys-SH and Cys-S-CAM, as shown on the $y$-axis in the figure. The same operation was repeated three times to obtain a reliable calibration curve.

[42], non-transmembrane classical PTPs [19], dual specificity phosphatases [16], and the low $M_{\mathrm{r}}$ PTP [43] has been demonstrated in various cell types. Together, such data suggest that the controlled production of cellular ROS may play a critical role in the inhibition of endogenous PTP activity, via modifications of the catalytic Cys residue, and in the regulation of tyrosine phosphorylation-dependent signaling.

Although the various methods described above allow identification of those PTPs that are oxidized in a cellular environment, they do not provide information on the extent of oxidation. Our MS-based strategy (summarized in Fig. 2) is a highly senstitive method capable of differentiating various states of oxidation of the catalytic Cys in PTPs. When used in conjunction with the above assays, it can generate a complete analysis of the oxidation of specific PTPs. Through application of this method, we have demonstrated that there is extensive oxidation of the catalytic Cys residue of endogenous PTP1B in response to ROS produced 

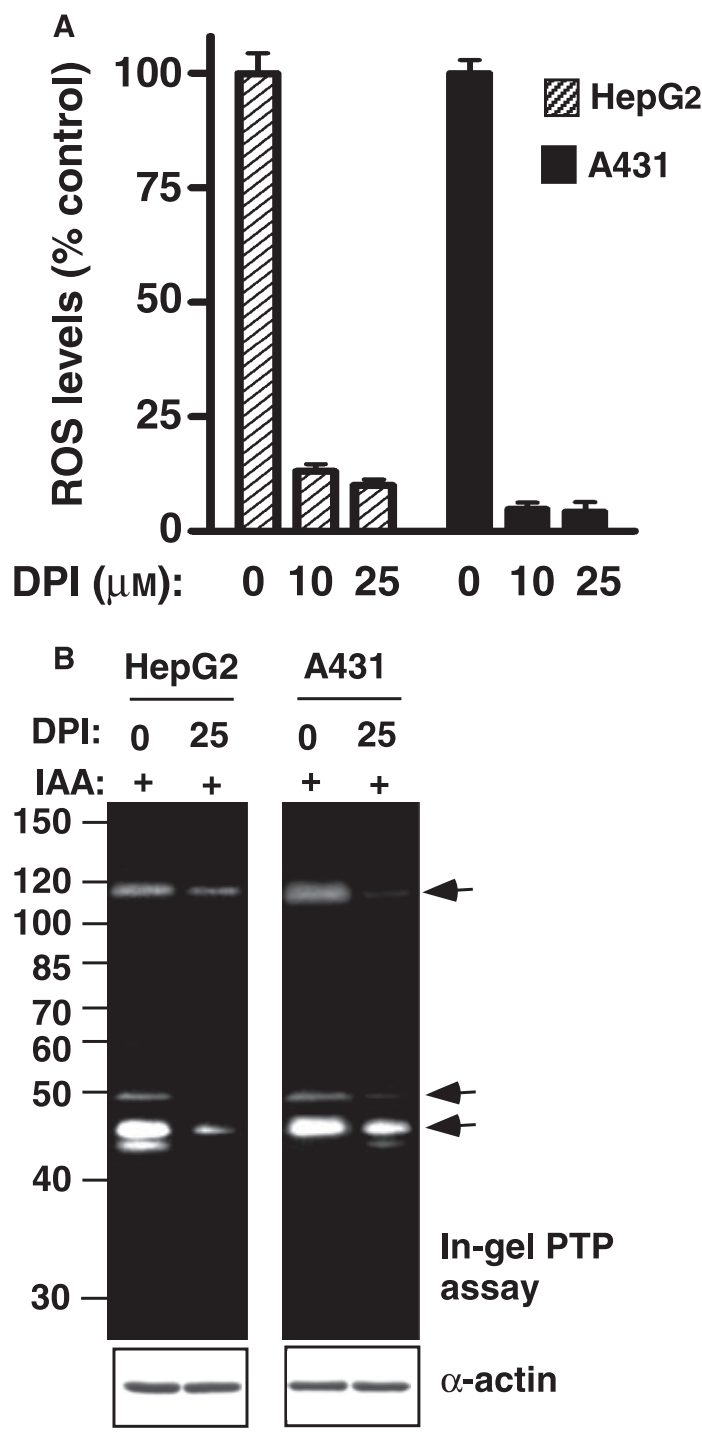

Fig. 11. Treatment of HepG2 and A431 cells with DPI led to reduction and reactivation of endogenous PTPs. For the experiments shown in $(A)$ and $(B)$, cells were plated in $10 \%$ fetal bovine serumcontaining medium for $16 \mathrm{~h}$, followed by treatment with DPI (Merck) in the serum-free medium for additional $8 \mathrm{~h}$. (A) The Amplex Red was used to determine the level of $\mathrm{H}_{2} \mathrm{O}_{2}$ released from cells cultured in the absence or presence (10 or $25 \mu \mathrm{M}$ ) of DPI. Data are shown are the mean \pm SE from triplicate experiments. (B) Cells were lysed in the presence of $100 \mathrm{~mm}$ iodoacetamide. An aliquot of total lysate $(25 \mu \mathrm{g})$ was subjected to an in-gel phosphatase activity assay or to immunoblotting with anti-actin serum. The arrowheads indicate the 115, 50 and 45 kDa PTPs for which reversible oxidation was decreased in the presence of DPI.

constitutively by HepG2 and A431 human cancer cells, which led to enzymatic inactivation of PTP1B. Remarkably, up to $\sim 50 \%$ of the endogenous PTP1B protein in A431 cells, and $\sim 25 \%$ in HepG2 cells, was subjected to reversible oxidation and inactivation, indicating the
A

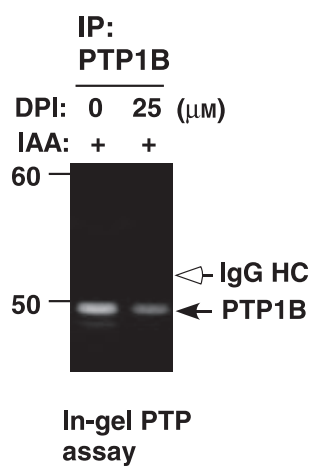

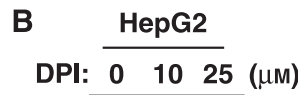

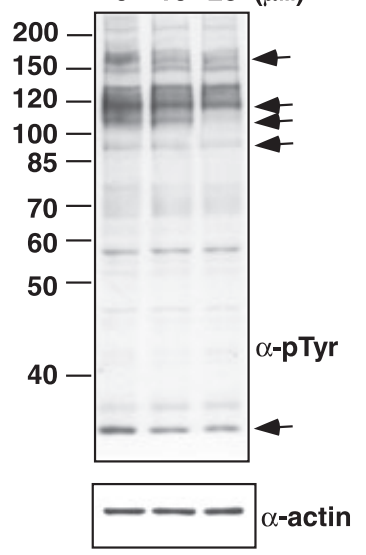

C

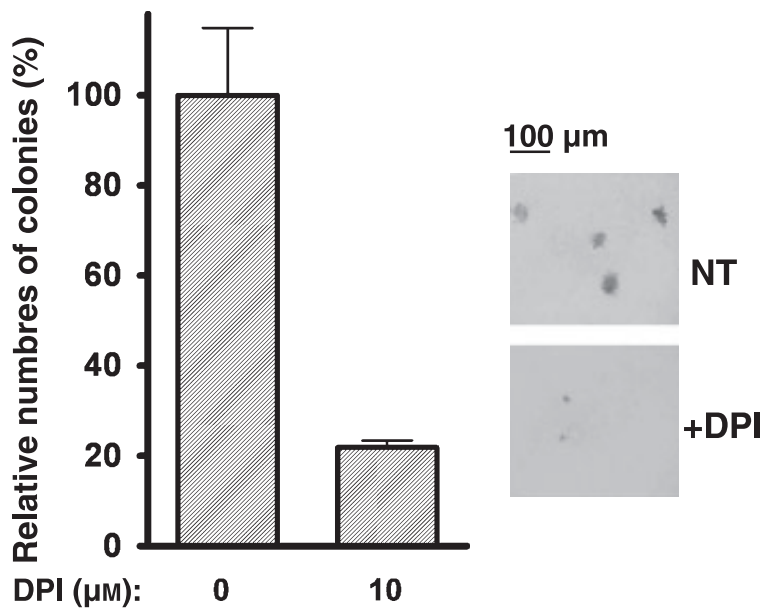

Fig. 12. ROS produced constitutively by HepG2 cells are essential for inactivation of endogenous PTP1B, tyrosine phosphorylation of cellular proteins and anchorage-independent cell growth. For experiments shown in (A) and (B), HepG2 cells were plated in 10\% fetal bovine serum-containing medium for $16 \mathrm{~h}$, followed by treatment with DPI in serum-free medium for additional $8 \mathrm{~h}$. (A) Cells were lysed in the presence of $100 \mathrm{~mm}$ iodoacetamide. An aliquot of total lysate $(1 \mathrm{mg})$ was incubated with FG6 antibody $(5 \mu \mathrm{g})$ for immunoprecipitation of endogenous PTP1B. The immunocomplex was subjected to an in-gel PTP activity assay. The arrowhead indicates the position of $50 \mathrm{kDa}$ PTP1B in an SDS/PAGE gel. (B) An aliquot of total lysate $(25 \mu \mathrm{g})$ obtained from DPI-treated HepG2 cells, was subjected to immunoblotting with anti-pTyr or anti-actin sera. Arrowheads indicate cellular proteins for which the tyrosine phosphorylation level was decreased concomitant with an increase of DPI concentration. (C) HepG2 cells were seeded at $1.5 \times 10^{3}$ per well in culture medium with $0.3 \%$ agar in a $60-\mathrm{mm}$ dish. Cells were maintained in the complete culture medium containing $10 \mu \mathrm{M}$ DPI for 2 weeks. The colonies larger than $50 \mu \mathrm{M}$ in diameter were counted under a microscope. Data shown are the mean \pm SE from triplicate samples in a representative experiment. Similar results were observed in three independent experiments. The results shown in the right panel illustrate the images of representative colonies of HepG2 cultured in the absence (NT) or presence (+DPI) of DPI. 
potential importance of this redox-dependent process in controlling the function of PTP1B, and presumably other PTPs, in the regulation of cell signaling. Indeed, our data indicate that the inhibition of ROS production by treatment of HepG2 cells with the Nox inhibitor DPI led to reduction and reactivation of PTPs, decreased tyrosine phosphorylation of cellular proteins and suppression of anchorage-independent growth.

Our implementation of this MS-based analysis revealed that the oxidation-induced Cys modification is a highly specific event. Data obtained from the analysis of $\mathrm{H}_{2} \mathrm{O}_{2}$-treated recombinant, C-terminally-truncated PTP1B demonstrated both the reversible and irreversible oxidation of the catalytic Cys215 (Fig. 3). By contrast, the other five Cys residues in PTP1B remained in the reduced state even when a high concentration of $\mathrm{H}_{2} \mathrm{O}_{2}$ was applied. Consistent with the results of in vitro experiments, we observed that only the catalytic Cys215, but not other Cys residues, of the endogenous PTP1B was oxidized by intracellular ROS in HepG2 and A431 cells (Figs 6 and 7). Therefore, our data illustrate that the low $\mathrm{pK} \alpha$ characteristic, which is contributed by the unique architecture of the active site of PTPs, is essential for the catalytic Cys residue to be targeted by ROS. Those Cys residues with a normal $\mathrm{pK} \alpha$ were resistant to oxidation even when PTPs were exposed to high concentrations of ROS in a transformed cell.

As revealed by the in-gel phosphatase activity assay (Fig. 1), our results showed that ROS selectively target a subset of cellular PTPs, rather than non-specifically oxidizing PTPs in general. In addition to PTP1B that has been characterized in the present study, two more PTPs were also reversibly oxidized in HepG2 and A431 cells. Our preliminary data suggest that the 115 and $45 \mathrm{kDa}$ phosphatases are PTP-PEST and TC-PTP, respectively (Y. W. Lou and T. C. Meng, unpublished results). The mechanism underlying the specificity of PTP oxidation remains unclear. One possibility is localized production of ROS, so that only PTPs located near the sources of ROS production would have the potential to be oxidized. In addition to Nox enzymes, which are located either on plasma membranes [44] or associated with internal membranes [45], mitochondria also contribute to ROS production in cells [46]. Recent studies have demonstrated that ROS produced by Nox enzymes $[7,47]$ or in the mitochondria $[48,49]$ may play an important role in the regulation of signaling events. It will be important to explore the exact sources of ROS that are responsible for oxidizing this subgroup of endogenous PTPs in HepG2 and A431 cells. Further investigations that characterize the regulation of the subcellular localization of PTP1B, PTP-PEST and TC-PTP would be helpful in revealing the underlying mechanisms contributing to the specificity of PTP oxidation in those cells.

It is likely that, due to their close proximity to plasma membrane-associated Nox enzymes, receptorlike PTPs (RPTPs) might be exposed to sources of ROS, and thus may be inactivated through an oxidation-dependent mechanism in cells. Consistent with this hypothesis, it has been reported that RPTPs are susceptible to oxidation $[42,50,51]$. Furthermore, it was shown that the invariant Cys residue in the D2 domain of RPTPs displays enhanced sensitivity compared to that in the D1 domain, and may function as a redox sensor $[50,51]$. However, it is important to note that we did not observe reversible oxidation of high $M_{\mathrm{r}}$ PTPs ( $>120 \mathrm{kDa}$ in the SDS/PAGE gels, where most RPTPs would be detected; Fig. 1). A previous study documented that RPTPs were unable to refold properly in the gel-based matrix, and therefore are unable to adopt an active conformation when examined by the in-gel phosphatase assay [52]. However, we anticipate that it may be possible to analyze the redox state of a given RPTP in an immunocomplex by combining chemical labeling with MS-based analysis.

Our MS results also revealed that cellular ROS not only induce reversible oxidation, but also trigger irreversible oxidation of PTP1B. Intriguingly, a significant fraction $(>30 \%)$ of PTP1B in HepG2 and A431 cells was in a permanently inactive state (Fig. 8). Furthermore, we observed that the relative amount of the $52 \mathrm{kDa}$ form of PTP1B remained constant in HepG2 cells treated with DPI for $8 \mathrm{~h}$, compared to that in untreated, control HepG2 cells (Y.W. Lou and T. C. Meng, unpublished results), suggesting that irreversibly oxidized PTP1B, similar to the unmodified protein, displayed a long half-life. This is consistent with the observation that higher order oxidation does not induce significant changes in overall structure $[12,14]$, and any subtle change of conformation at the active site is not sufficient to trigger the cellular machinery for rapid degradation of such irreversibly oxidized forms of PTP1B. Although human cancer cells, such as hepatoma cells, express high levels of glutathione [53] that may facilitate reduction and reactivation of reversibly oxidized PTPs, apparently there are sufficient levels of constitutively produced ROS to result in the eventual terminal oxidation of a portion of the pool of PTPs. The present study demonstrates that irreversible oxidation of endogenous PTPs indeed occurs in response to cellular ROS. Thus, the highly oxidized and permanently inactivated forms of these PTPs may not be merely irrelevant products triggered by oxidative reactions in vitro. It has been reported that highly oxidized PTPs may function as substrate 
traps [54]; however, in preliminary studies, we did not find the sulfonic acid form of PTP1B to be associated with any phosphoproteins in pervanadate-treated HepG2 cell lysates (data not shown). Further investigations are needed to delineate the exact role of such irreversibly oxidized PTPs in the control of tyrosine phosphorylation-dependent signaling.

In summary, the present study employed an MS-based analysis to quantitate the oxidation status of the active site Cys residue of endogenous PTP1B in HepG2 and A431 cells. We have shown that oxidation of PTP1B occurs to high stiochiometry; however, this covalent modification is specific to the active site Cys residue, emphasizing its potential as a mechanism for regulation of cell signaling, rather than a consequence of non-specific damage induced by ROS. Furthermore, we have demonstrated that treatment of these cells with DPI, which inhibits ROS production, inhibits reversible oxidation and inactivation of the PTPs, concomitant with decreased levels of tyrosine phosphorylation and inhibition of the transformed phenotype. It is interesting to note that, although the number of large HepG2 cell colonies was significantly decreased in response to DPI treatment (Fig. 10C), when the total number of colonies in the soft agar medium was counted regardless of size, we observed only a marginal difference between samples growing in the absence or presence of DPI after 2 weeks of incubation (data not shown). Thus, our results suggest that redox regulation of PTPs may be an important element in the control of cell proliferation, rather than survival, for maintaining the transformed phenotype of some cancer cells. It has been reported previously that, similar to HepG2 and A431 cells, various other cancer cells constitutively produce high levels of ROS. It will be intriguing to identify the redox status of PTPs in those cell types by application of this MS-based analysis to address how broadly the oxidation and inactivation of PTPs contributes to abnormal signaling events in cancer cells. Furthermore, we propose that the MS-based method can be used to identify and characterize the redox status of enzymes across the PTP superfamily under various physiological and pathophysiological conditions. Such information will be essential for us to gain insight into the important function of PTPs in the control of a diverse array of signal transduction pathways.

\section{Experimental procedures}

\section{In vitro oxidation of PTP1B}

The C-terminally-truncated, $37 \mathrm{kDa}$ form of human PTP1B was purified to homogeneity as described previ- ously [55]. PTP1B at a concentration of $3 \mu \mathrm{M}$ in degassed buffer (20 mm Hepes pH 7.5, 1\% NP-40, $150 \mathrm{~mm} \mathrm{NaCl}$, $10 \%$ glycerol, $20 \mu \mathrm{M}$ dithiothreitol) was treated with $\mathrm{H}_{2} \mathrm{O}_{2}$ for 10 min. The oxidation reaction was stopped by addition of recombinant catalase (Merck, Whitehouse Station, NJ, USA). The oxidized PTP1B was subsequently reacted with $100 \mathrm{~mm}$ iodoacetamide (Sigma-Aldrich, Munich, Germany) at $25^{\circ} \mathrm{C}$ for $30 \mathrm{~min}$ in the dark. Excess iodoacetamide was then removed by gel filtration on a PD-10 desalting column (Amersham Biosciences, Orsay, France). For analysis with antibody to the terminally oxidized form of PTP1B, purified recombinant protein was either left untreated, or reacted with $200 \mu \mathrm{M}$ $\mathrm{H}_{2} \mathrm{O}_{2}$ at room temperature for $10 \mathrm{~min}$. The reaction was terminated by addition of gel loading buffer, and samples were subjected to reducing SDS/PAGE and immunoblotted with mouse anti-(oxidized PTP active site) serum (clone 335636, purchased from R\&D Systems, Inc., Minneapolis, MN, USA).

\section{Cell culture}

Cells were routinely maintained in DMEM (Invitrogen, Karlsruhe, Germany) supplemented with $10 \%$ fetal bovine serum (HepG2, A431, HeLa and Caco-2) or 10\% calf serum (Rat-1 and NIH3T3). For measurement of ROS levels, cells were seeded in 96 -well plates at $1.5 \times 10^{4}$ cells per well and incubated overnight prior to analysis. For in-gel phosphatase activity assay, immunoblotting and immunoprecipitation, cells were seeded at a density of $1 \times 10^{7}$ cells per $15-\mathrm{cm}$ plate for $48 \mathrm{~h}$ in complete medium, followed by serum deprivation for $16 \mathrm{~h}$ prior to cell lysis.

\section{Measurement of ROS level}

Prior to measurement, cells were washed once with serumfree Krebs-Ringer phosphate glucose buffer (KRPG: $145 \mathrm{~mm} \mathrm{NaCl}, 5.7 \mathrm{~mm}$ sodium phosphate $\mathrm{pH} 7.35$, $4.86 \mathrm{~mm} \mathrm{KCl}, 0.54 \mathrm{~mm} \mathrm{CaCl}_{2}, 1.22 \mathrm{~mm} \mathrm{MgSO}_{4}, 5.5 \mathrm{~mm}$ glucose). Cells were incubated with reaction mixture containing $50 \mu \mathrm{M}$ Amplex Red reagent (Invitrogen) and $0.1 \mathrm{U} \cdot \mathrm{mL}^{-1}$ horseradish peroxidase in serum-free KRPG buffer at $37^{\circ} \mathrm{C}$ for different time periods, as indicated in the figures. The intensity of $\mathrm{H}_{2} \mathrm{O}_{2}$-induced fluorescence was quantitated by a fluorescence microplate reader (Beckman Coulter, Fullerton, CA, USA) with excitation at $530 \mathrm{~nm}$ and emission at $620 \mathrm{~nm}$.

\section{In-gel PTP activity assay}

This method was originally described by Burridge and Nelson [52], and then modified by Meng and Tonks [40,56]. Briefly, cells were harvested under anaerobic conditions (lysis buffer degassed using $30 \mathrm{in}-\mathrm{Hg}$ vacuum for $30 \mathrm{~min}$ 
and supplemented with $100 \mu \mathrm{g} \cdot \mathrm{mL}^{-1}$ catalase and $100 \mu \mathrm{g} \cdot \mathrm{mL}^{-1}$ superoxide dismutase; Sigma-Aldrich). Samples from various sources were applied to a $10 \%$ SDS-gel cast to contain ${ }^{32} \mathrm{P}$-labeled poly(Glu : Tyr $)_{4: 1}$ as substrate $\left(1.5 \times 10^{6} \mathrm{cpm}\right.$ per $20 \mathrm{~mL}$ of gel solution, $\sim 2 \mu \mathrm{M}$ pTyr $)$. Following electrophoresis, the gel was placed sequentially in buffers for fixation, denaturation and renaturation. During the last wash with renaturation buffer overnight, $3 \mathrm{~mm}$ dithiothreitol was included to reduce and activate those PTPs that had become oxidized, thus leading to dephosphorylation of substrate immediately surrounding the area occupied by the phosphatase in the gel. The reaction was terminated with staining solution containing Coomassie Blue. After destaining, the gel was dried and then exposed to X-ray film.

\section{Immunoprecipitation of endogenous PTP1B}

All buffers were degassed prior to use. Cells were rinsed with $\mathrm{NaCl} / \mathrm{Pi}$, then lysed in ice-cold lysis buffer $(50 \mathrm{~mm}$ Hepes pH 7.5, 1\% NP-40, $150 \mathrm{~mm} \mathrm{NaCl}, 10 \mathrm{~mm} \mathrm{NaF}$, $10 \%$ glycerol, $\quad 10 \mathrm{mM} \quad \mathrm{Na}_{4} \mathrm{P}_{2} \mathrm{O}_{7}, \quad 0.1 \mathrm{U} \cdot \mu \mathrm{L}^{-1}$ catalase, $0.1 \mathrm{U} \cdot \mu \mathrm{L}^{-1}$ superoxide dismutase, protease inhibitors $100 \mathrm{~mm}$ iodoacetamide). An aliquot of lysate (in total $\sim 35 \mathrm{mg}$ for each immunoprecipitation) was incubated with $\sim 30 \mu \mathrm{g}$ of antibody FG6 conjugated to protein A-Sepharose (Amersham Biosciences) at $4{ }^{\circ} \mathrm{C}$ for $7 \mathrm{~h}$. This reaction led to the complete immunodepletion of PTP1B from lysates (data not shown). The immunecomplexes were washed five times with ice-cold, degassed lysis buffer. Proteins were extracted from Sepharose beads by SDS/PAGE gel loading buffer containing $650 \mathrm{~mm} \quad \beta$-mercaptoethanol, which reduced those PTP1B molecules that had been reversibly oxidized in cells. The extracted proteins were boiled and then subjected to SDS/PAGE. For analysis with antibody to the terminally oxidized form of PTP1B, A431 cells were serum starved for $16 \mathrm{~h}$ then lysed in the ice-cold, degassed lysis buffer. An aliquot of total lysate $(1.5 \mathrm{mg})$ was incubated with $5 \mathrm{mg}$ rabbit anti-PTP1B serum (\#AF1366; R\&D Systems, Inc.), which had been conjugated to protein A-sepharose (Amersham Biosciences), at $4{ }^{\circ} \mathrm{C}$ for $3 \mathrm{~h}$. The immunocomplexes were washed three times with the degassed lysis buffer, then immunoblotted with anti-(oxidized PTP active site) serum (clone 335636; R\&D Systems, Inc.) or mouse anti-PTP1B serum FG6.

\section{In-gel digestion with trypsin or endoproteinase Arg-C}

The protein band of interest was manually excised from an SDS-gel and repeatedly destained in acetonitrile until the gel slice became colorless. The processed gel slices were then dried by speed vacuum. In-gel digestion was performed by adding trypsin (Promega, Madison, WI, USA) or endoproteinase Arg-C (Roche Applied Science, Mannheim,
Germany) in $25 \mathrm{~mm}$ ammonium bicarbonate buffer, followed by incubation at $37^{\circ} \mathrm{C}$ for $16 \mathrm{~h}$ with vortexing. The digested peptides were then recovered from the gel by sequential extractions with acetonitrile. All extracts were pooled and dried for MALDI-MS and MS/MS analyses.

\section{MALDI-MS and MS/MS analysis}

MALDI-MS detection and MS/MS sequencing of peptides were performed on either a Q-TOF Ultima ${ }^{\text {TM }}$ MALDI (Waters, Manchester, UK) or a 4700 Proteomics Analyzer (Applied Biosystems, Framingham, MA, USA), both operated in reflectron positive ion mode. For data acquisition on the Q-TOF mass spectrometer, proteolytic peptides were mixed with a solution of $\alpha$-cyano-4-hydroxycinnamic acid $\left(6 \mathrm{mg} \cdot \mathrm{mL}^{-1}\right)$ in $50 \%$ acetonitrile $/ 0.1 \%$ formic acid prior to spotting onto the 96-well format target plate. Data were automatically processed by PGS software, release 2.1 (Micromass, Manchester, UK) and searched against SWISSPROT database using MASCOT for protein identification purposes, as described previously [57]. Raw data were further processed manually using MASSLYNX, release 4.0 (Micromass) and examined in detail for identification of the Cys-containing peptides. For data acquisition on the 4700 Proteomics Analyzer, the digested peptide samples were dissolved in $50 \%$ acetonitrile $/ 0.1 \%$ formic acid and premixed with a matrix solution of $\alpha$-cyano-4-hydroxycinnamic acid $\left(5 \mathrm{mg} \cdot \mathrm{mL}^{-1}\right)$ in $70 \%$ acetonitrile $/ 0.1 \%$ formic acid for spotting onto the target plate. For collision-induced dissociation MS/MS, the indicated collision cell pressure was increased from $3.0 \times 10^{-8}$ torr (no collision gas) to $5.0 \times 10^{-7}$ torr, with the potential difference between the source acceleration voltage and the collision cell set at $1 \mathrm{kV}$. The resolution of timed ion selector for precursor ion was set at 200, which would allow in a mass window of $\sim 10 \mathrm{Da}$ for precursors at $m / z$ 2000. The mass and tandem mass spectra were analyzed MASCOT (Matrix Science, London, UK; available at http://www.matrixscience.com). Parameters used for queries were programmed so that trypsin-cleaved peptides, peptides with one missed cleavage by trypsin, and peptides containing various modifications, including Cys carbamidomethylation, Met oxidation and Ser/Thr/Tyr phosphorylation, can be revealed. Peptides and MS/MS tolerance for MALDI-TOF-TOF were set at 0.25 Da. Protein identification was considered as significant if the MASCOT score was higher than that of a random match at $P<0.05$. MS/MS spectral assignments for de novo sequencing and identification of site-specific Cys oxidation were performed manually.

\section{Soft agar assay for anchorage-independent cell growth}

Trypsinized HepG2 cells were resuspended in culture medium containing $0.3 \%$ agar (Difco, Sperks, MD, USA). 
For plating, $1.5 \times 10^{3}$ cells in $1 \mathrm{~mL}$ of suspension were laid on the top of $4 \mathrm{~mL}$ of solidified culture medium containing $0.5 \%$ agar in a $60 \mathrm{~mm}$ dish. One day after plating, $1 \mathrm{~mL}$ of complete culture medium containing $10 \%$ fetal bovine serum in the presence or absence of $10 \mu \mathrm{M}$ DPI was added per dish. The medium was refreshed every 3 days. After 2 weeks of incubation, culture medium was removed and $0.5 \mathrm{~mL}$ of Crystal Violet $(0.005 \%$; Sigma-Aldrich) was added to each plate to visualize cell colonies, which were then recorded by photography using a phase-contrast microscope. Only those colonies larger than $50 \mathrm{~mm}$ in diameter were counted.

\section{Acknowledgements}

This work was supported by Grants NSC-94-2311-B001-032, NSC-95-2311-B-001-011 (to TCM), NSC-943112-B-001-009-Y and NSC-95-3112-B-001-014 (to the National Proteomic Core Facility) from National Science Council, Taiwan, and R01 grants GM55989 and CA53840 from the National Institutes of Health, USA (to NKT). We also acknowledge support from Academia Sinica (to TCM and KHK). We are grateful to Andrew H.-J. Wang (Director of National Core Facility for Proteomics Research, Academia Sinica) for his enthusiastic support of this work.

\section{References}

1 Andersen JN, Jansen PG, Echwald SM, Mortensen OH, Fukada T, Del Vecchio R, Tonks NK \& Moller NP (2004) A genomic perspective on protein tyrosine phosphatases: gene structure, pseudogenes, and genetic disease linkage. FASEB J 18, 8-30.

2 Alonso A, Sasin J, Bottini N, Friedberg I, Osterman A, Godzik A, Hunter T, Dixon J \& Mustelin T (2004) Protein tyrosine phosphatases in the human genome. Cell 117, 699-711.

3 Lohse DL, Denu JM, Santoro N \& Dixon JE (1997) Roles of aspartic acid-181 and serine-222 in intermediate formation and hydrolysis of the mammalian proteintyrosine-phosphatase PTP1. Biochemistry 36, 4568-4575.

4 Zhang ZY \& Dixon JE (1993) Active site labeling of the Yersinia protein tyrosine phosphatase: the determination of the $\mathrm{pKa}$ of the active site cysteine and the function of the conserved histidine 402. Biochemistry 32, 9340-9345.

5 Denu JM \& Tanner KG (1998) Specific and reversible inactivation of protein tyrosine phosphatases by hydrogen peroxide: evidence for a sulfenic acid intermediate and implications for redox regulation. Biochemistry 37, 5633-5642.

6 Bokoch GM \& Knaus UG (2003) NADPH oxidases: not just for leukocytes anymore! Trends Biochem Sci 28, 502-508.
7 Lambeth JD (2004) NOX enzymes and the biology of reactive oxygen. Nat Rev Immunol 4, 181-189.

8 Mahadev K, Motoshima H, Wu X, Ruddy JM, Arnold RS, Cheng G, Lambeth JD \& Goldstein BJ (2004) The NAD(P)H oxidase homolog Nox4 modulates insulinstimulated generation of $\mathrm{H}_{2} \mathrm{O}_{2}$ and plays an integral role in insulin signal transduction. Mol Cell Biol 24, 18441854.

9 Park HS, Jung HY, Park EY, Kim J, Lee WJ \& Bae YS (2004) Cutting edge: direct interaction of TLR4 with $\mathrm{NAD}(\mathrm{P}) \mathrm{H}$ oxidase 4 isozyme is essential for lipopolysaccharide-induced production of reactive oxygen species and activation of NF-kappa B. J Immunol 173, 3589-3593.

10 Finkel T (2003) Oxidant signals and oxidative stress. Curr Opin Cell Biol 15, 247-254.

11 Rhee SG, Bae YS, Lee SR \& Kwon J (2000) Hydrogen peroxide: a key messenger that modulates protein phosphorylation through cysteine oxidation. Sci STKE 2000, PE1.

12 Salmeen A, Andersen JN, Myers MP, Meng TC, Hinks JA, Tonks NK \& Barford D (2003) Redox regulation of protein tyrosine phosphatase 1B involves a sulphenylamide intermediate. Nature 423, 769-773.

13 Salmeen A \& Barford D (2005) Functions and mechanisms of redox regulation of cysteine-based phosphatases. Antioxid Redox Signal 7, 560-577.

14 van Montfort RL, Congreve M, Tisi D, Carr R \& Jhoti $\mathrm{H}$ (2003) Oxidation state of the active-site cysteine in protein tyrosine phosphatase 1B. Nature 423, 773-777.

15 Bae YS, Kang SW, Seo MS, Baines IC, Tekle E, Chock PB \& Rhee SG (1997) Epidermal growth factor (EGF)induced generation of hydrogen peroxide. Role in EGF receptor-mediated tyrosine phosphorylation. $J$ Biol Chem 272, 217-221.

16 Kamata H, Honda S, Maeda S, Chang L, Hirata H \& Karin M (2005) Reactive oxygen species promote TNFalpha-induced death and sustained JNK activation by inhibiting MAP kinase phosphatases. Cell 120, 649-661.

17 Mahadev K, Zilbering A, Zhu L \& Goldstein BJ (2001) Insulin-stimulated hydrogen peroxide reversibly inhibits protein-tyrosine phosphatase $1 \mathrm{~b}$ in vivo and enhances the early insulin action cascade. J Biol Chem 276, 21938-21942.

18 Meng TC, Buckley DA, Galic S, Tiganis T \& Tonks NK (2004) Regulation of insulin signaling through reversible oxidation of the protein-tyrosine phosphatases TC45 and PTP1B. J Biol Chem 279, 37716-37725.

19 Meng TC, Fukada T \& Tonks NK (2002) Reversible oxidation and inactivation of protein tyrosine phosphatases in vivo. Mol Cell 9, 387-399.

20 Singh SV, Srivastava SK, Choi S, Lew KL, Antosiewicz J, Xiao D, Zeng Y, Watkins SC, Johnson CS, Trump DL et al. (2005) Sulforaphane-induced cell 
death in human prostate cancer cells is initiated by reactive oxygen species. J Biol Chem 280, 1991119924.

21 Sundaresan M, Yu ZX, Ferrans VJ, Irani K \& Finkel T (1995) Requirement for generation of $\mathrm{H}_{2} \mathrm{O}_{2}$ for plateletderived growth factor signal transduction. Science $\mathbf{2 7 0}$, 296-299.

22 Lambeth JD (2007) Nox enzymes, ROS, and chronic disease: an example of antagonistic pleiotropy. Free Radic Biol Med 43, 332-347.

23 Szatrowski TP \& Nathan CF (1991) Production of large amounts of hydrogen peroxide by human tumor cells. Cancer Res 51, 794-798.

24 Arnold RS, Shi J, Murad E, Whalen AM, Sun CQ, Polavarapu R, Parthasarathy S, Petros JA \& Lambeth JD (2001) Hydrogen peroxide mediates the cell growth and transformation caused by the mitogenic oxidase Nox1. Proc Natl Acad Sci USA 98, 5550-5555.

25 Mitsushita J, Lambeth JD \& Kamata T (2004) The superoxide-generating oxidase Nox1 is functionally required for Ras oncogene transformation. Cancer Res 64, 3580-3585.

26 Suh YA, Arnold RS, Lassegue B, Shi J, Xu X, Sorescu D, Chung AB, Griendling KK \& Lambeth JD (1999) Cell transformation by the superoxide-generating oxidase Mox1. Nature 401, 79-82.

27 Cross AR \& Jones OT (1986) The effect of the inhibitor diphenylene iodonium on the superoxide-generating system of neutrophils. Specific labelling of a component polypeptide of the oxidase. Biochem $J$ 237, 111-116.

28 Rhee SG (2006) Cell signaling. H2O2, a necessary evil for cell signaling. Science 312, 1882-1883.

29 Terada LS (2006) Specificity in reactive oxidant signaling: think globally, act locally. J Cell Biol 174, 615-623.

30 Krieger-Brauer HI, Medda PK \& Kather H (1997) Insulin-induced activation of NADPH-dependent $\mathrm{H} 2 \mathrm{O} 2$ generation in human adipocyte plasma membranes is mediated by Galphai2. J Biol Chem 272, 10135-10143.

31 Sattler M, Winkler T, Verma S, Byrne CH, Shrikhande G, Salgia R \& Griffin JD (1999) Hematopoietic growth factors signal through the formation of reactive oxygen species. Blood 93, 2928-2935.

32 Brumell JH, Burkhardt AL, Bolen JB \& Grinstein S (1996) Endogenous reactive oxygen intermediates activate tyrosine kinases in human neutrophils. $J$ Biol Chem 271, 1455-1461.

33 Giannoni E, Buricchi F, Raugei G, Ramponi G \& Chiarugi $P$ (2005) Intracellular reactive oxygen species activate Src tyrosine kinase during cell adhesion and anchoragedependent cell growth. Mol Cell Biol 25, 6391-6403.

34 Tonks NK (2005) Redox redux: revisiting PTPs and the control of cell signaling. Cell 121, 667-670.

35 Barford D (2004) The role of cysteine residues as redoxsensitive regulatory switches. Curr Opin Struct Biol 14, 679-686.
36 Hecht D \& Zick Y (1992) Selective inhibition of protein tyrosine phosphatase activities by $\mathrm{H} 2 \mathrm{O} 2$ and vanadate in vitro. Biochem Biophys Res Commun 188, 773-779.

37 Sullivan SG, Chiu DT, Errasfa M, Wang JM, Qi JS \& Stern A (1994) Effects of $\mathrm{H} 2 \mathrm{O} 2$ on protein tyrosine phosphatase activity in HER14 cells. Free Radic Biol Med 16, 399-403.

38 Lee SR, Kwon KS, Kim SR \& Rhee SG (1998) Reversible inactivation of protein-tyrosine phosphatase $1 \mathrm{~B}$ in A431 cells stimulated with epidermal growth factor. $J$ Biol Chem 273, 15366-15372.

39 Kwon J, Qu CK, Maeng JS, Falahati R, Lee C \& Williams MS (2005) Receptor-stimulated oxidation of SHP2 promotes T-cell adhesion through SLP-76-ADAP. EMBO J 24, 2331-2341.

40 Meng TC \& Tonks NK (2003) Analysis of the regulation of protein tyrosine phosphatases in vivo by reversible oxidation. Methods Enzymol 366, 304-318.

41 Markova B, Gulati P, Herrlich PA \& Bohmer FD (2005) Investigation of protein-tyrosine phosphatases by in-gel assays. Methods 35, 22-27.

42 Groen A, Lemeer S, van der Wijk T, Overvoorde J, Heck AJ, Ostman A, Barford D, Slijper M \& den Hertog J (2005) Differential oxidation of protein-tyrosine phosphatases. J Biol Chem 280, 10298-10304.

43 Nimnual AS, Taylor LJ \& Bar-Sagi D (2003) Redoxdependent downregulation of Rho by Rac. Nat Cell Biol 5, 236-241.

44 Cheng G \& Lambeth JD (2004) NOXO1, regulation of lipid binding, localization, and activation of Nox 1 by the Phox homology (PX) domain. J Biol Chem 279, 4737-4742.

45 Martyn KD, Frederick LM, von Loehneysen K, Dinauer MC \& Knaus UG (2006) Functional analysis of Nox4 reveals unique characteristics compared to other NADPH oxidases. Cell Signal 18, 69-82.

46 Chance B, Sies H \& Boveris A (1979) Hydroperoxide metabolism in mammalian organs. Physiol Rev 59, 527605.

47 Lambeth JD (2002) Nox/Duox family of nicotinamide adenine dinucleotide (phosphate) oxidases. Curr Opin Hematol 9, 11-17.

48 Hool LC (2006) Reactive oxygen species in cardiac signalling: from mitochondria to plasma membrane ion channels. Clin Exp Pharmacol Physiol 33, 146151.

49 Werner E \& Werb Z (2002) Integrins engage mitochondrial function for signal transduction by a mechanism dependent on Rho GTPases. J Cell Biol 158, 357-368.

50 Persson C, Sjoblom T, Groen A, Kappert K, Engstrom U, Hellman U, Heldin CH, den Hertog J \& Ostman A (2004) Preferential oxidation of the second phosphatase domain of receptor-like PTP-alpha revealed by an antibody against oxidized protein tyrosine phosphatases. Proc Natl Acad Sci USA 101, 1886-1891. 
51 van der Wijk T, Blanchetot C, Overvoorde $\mathbf{J}$ \& den Hertog J (2003) Redox-regulated rotational coupling of receptor protein-tyrosine phosphatase alpha dimers. $J$ Biol Chem 278, 13968-13974.

52 Burridge K \& Nelson A (1995) An in-gel assay for protein tyrosine phosphatase activity: detection of widespread distribution in cells and tissues. Anal Biochem 232, 56-64.

53 Huang ZZ, Chen C, Zeng Z, Yang H, Oh J, Chen L \& Lu SC (2001) Mechanism and significance of increased glutathione level in human hepatocellular carcinoma and liver regeneration. FASEB $J \mathbf{1 5}, 19-21$.

54 Herrlich P \& Bohmer FD (2000) Redox regulation of signal transduction in mammalian cells. Biochem Pharmacol 59, 35-41.
55 Barford D, Keller JC, Flint AJ \& Tonks NK (1994) Purification and crystallization of the catalytic domain of human protein tyrosine phosphatase $1 \mathrm{~B}$ expressed in Escherichia coli. J Mol Biol 239, 726-730.

56 Meng TC, Hsu SF \& Tonks NK (2005) Development of a modified in-gel assay to identify protein tyrosine phosphatases that are oxidized and inactivated in vivo. Methods 35, 28-36.

57 Lee CL, Hsiao HH, Lin CW, Wu SP, Huang SY, Wu CY, Wang AH \& Khoo KH (2003) Strategic shotgun proteomics approach for efficient construction of an expression map of targeted protein families in hepatoma cell lines. Proteomics 3, 2472-2486. 